\title{
Suíte Vera Cruz: samba, maracatu e ijexá em adaptações a
}

\section{compassos mistos}

\author{
Raphael Ferreira da Silva
}

Universidade Federal de Uberlândia | Brasil

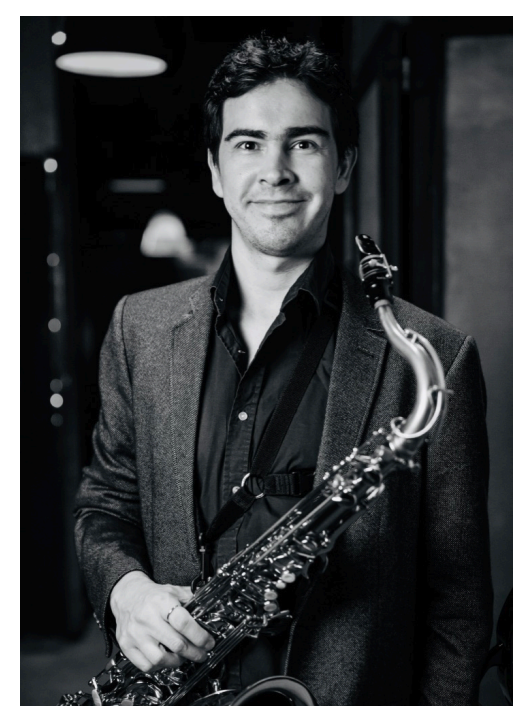

Raphael Ferreira é saxofonista, compositor e arranjador, tendo lançado nove discos entre projetos como solista ou colíder. Em colaboraçôes ou como sideman, tem trabalhos realizados com Banda Urbana, Grupo Comboio, Grupo Amanajé, Airto Moreira, Flora Purim, Arismar do Espírito Santo, Filó Machado, Nelson Sargento, Phil DeGreg, Letieres Leite e Rosa Passos, tendo excursionado pelas Américas do Sul e Norte, Europa e Marrocos; nesta atividade, destaca-se sua atuação junto ao grupo Hermeto Pascoal \& Big Band, premiado no Latin Grammy 2018. Ferreira é Doutor em Música pela Unicamp e realizou Pós-Doutorado pela University of North Texas/EUA; atualmente é professor da Universidade Federal de Uberlândia.

E-mail: raphaelphferreira@gmail.com

Website: www.raphaelferreira.net 
Suíte Vera Cruz é produto de um estudo teórico-prático em que explorei diferentes
configurações de compassos mistos como ignições combinatórias para um processo de
composição musical academicamente orientada, tendo como linhas delimitadoras os gêneros samba ${ }^{1}$, maracatu e ijexá. Considero que tal resultado comunica, como afirma Borgdorff (2017, p. 320) "as descobertas artísticas tanto cognitivamente quanto artisticamente. Longe de ser uma mera ilustração que acompanha a pesquisa, os resultados artísticos assim formam um componente indispensável da mesma.” Corroborando com esta perspectiva, López-Cano (2015, p. 79) escreve que o produto artístico "pode-se considerar como uma instância que gera conhecimento através da experiência estética em suas múltiplas interpretações.”

Em linhas gerais, na construção composicional as decisões foram norteadas pela minha bagagem no contexto estético da música brasileira instrumental “jazzisticamente orientada”; desta forma, na peça podem ser observados elementos técnico-musicais presentes na bibliografia, discografia e repertório tanto da música brasileira popular quanto do jazz.

Devido ao perfil da minha atuação como compositor, arranjador e instrumentista, optei pela formação de noneto, que contempla trompete/flugelhon, sax soprano/sax alto, sax tenor, sax barítono, guitarra elétrica, piano, baixo elétrico, bateria e percussão. Os espaços abertos à improvisação foram arbitrariamente destinados aos saxofones soprano, alto e tenor, além de guitarra, piano e bateria; adotei este recurso como mecanismo de estruturação nas seçốes formais de desenvolvimento, em segmentos deliberadamente estruturados para que houvesse uma abertura à indeterminação.

Para a escrita musical propriamente dita, realizei estudos com vistas a encontrar a forma de notação rítmica mais eficiente para o trabalho em questão; assim, na maior parte da peça optei pela soma de duas fórmulas de compasso diferentes, no intuito de explicitar a subdivisão adotada tanto na melodia quanto na levada designada à seção rítmico-harmônica. Para o registro em partitura foi utilizado o software Sibelius (versão 8.5).

As presentes grades estão disponíveis também em formato de vídeo-partitura no YouTube ${ }^{2}$. As gravações podem ser acessadas ainda nas plataformas de streaming de música, como Spotify, Deezer,

\footnotetext{
${ }^{1} \mathrm{O}$ movimento denominado 'Samba de Aruak' foi apresentado em comunicação-difusão no XXXI Congresso da Associação Nacional de Pesquisa e Pós-Graduação em Música (ANPPOM).

${ }^{2}$ Link: https://www.youtube.com/playlist?list=PL3rrZMbh6ySH2 94mkat9cISJCe6_N1KQ
} 
Tidal, Apple Music e similares ${ }^{3}$.

\section{REFERÊNCIAS}

BORGDORFF, Henk. O conflito das faculdades: sobre teoria, prática e pesquisa em academias profissionais de artes. Trad.: Daniel Lemos Cerqueira. Opus, v. 23, n. 1, p. 314-323, abr. 2017.

LÓPEZ-CANO, Rubén. Pesquisa artística, conhecimento musical e a crise da contemporaneidade. Art Research Journal, V. 2, n. 1, p. 69-94. Brasil: jan. / jun. 2015.

\footnotetext{
${ }^{3}$ Link: https://tratore.ffm.to/suiteveracruz
} 
PARTITURA TRANSPOSTA

$$
\delta^{\prime}=188
$$

\section{SUÍTE VERA CRUL I-SAMBA DE ARUAK}

RAPHAEL FERREIRA

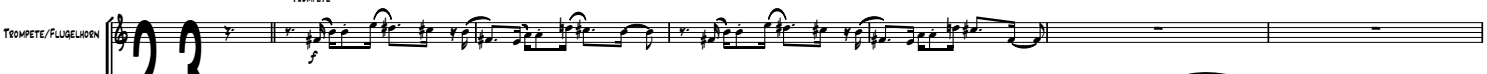
(n)

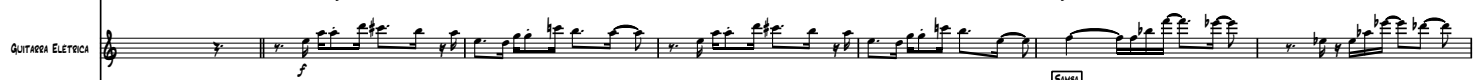
mans

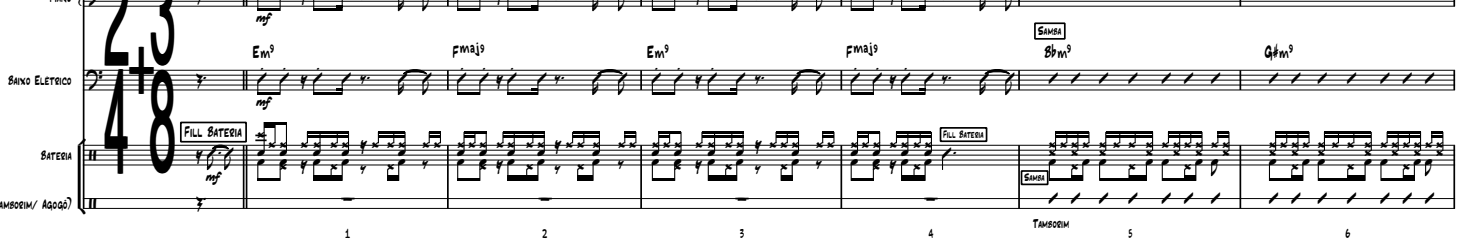
$=$

[]

mollon

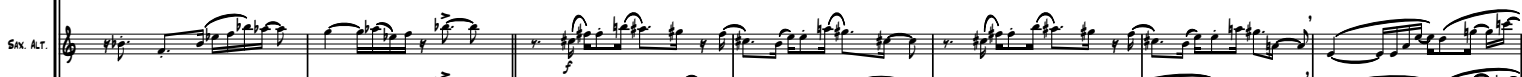

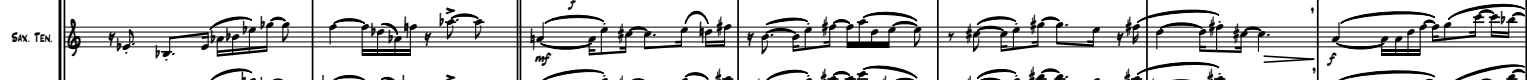

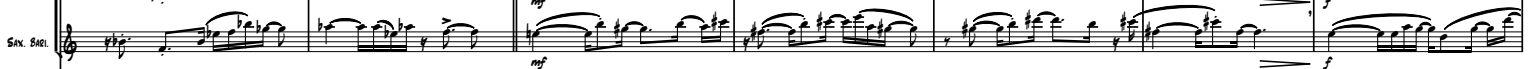

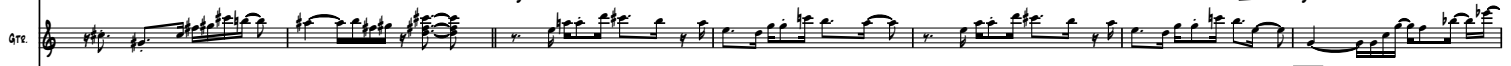

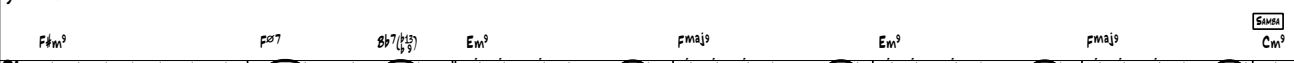
misher Ftam * WhW

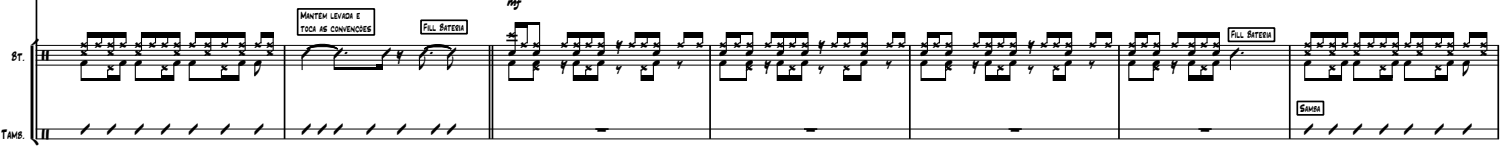

$\geqslant$

(n) Sxar sxsa

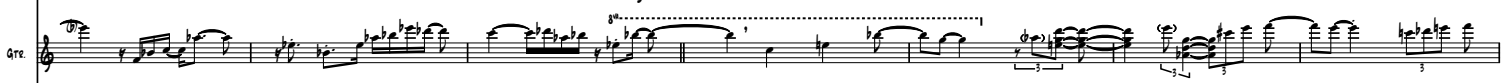

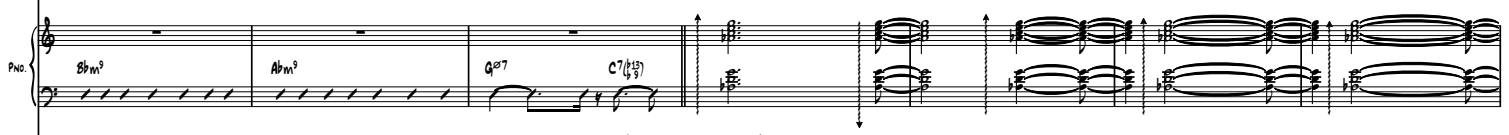
som sine 

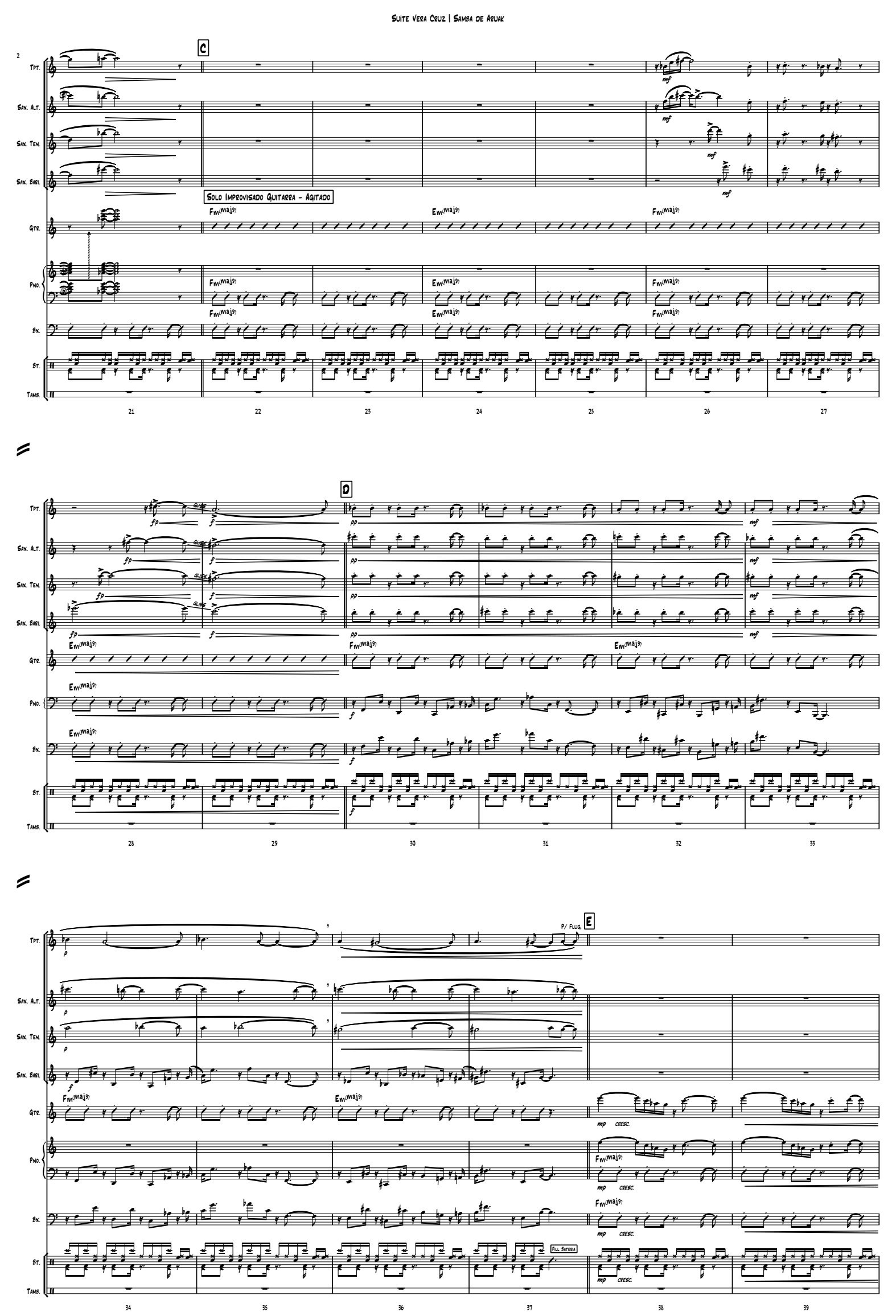

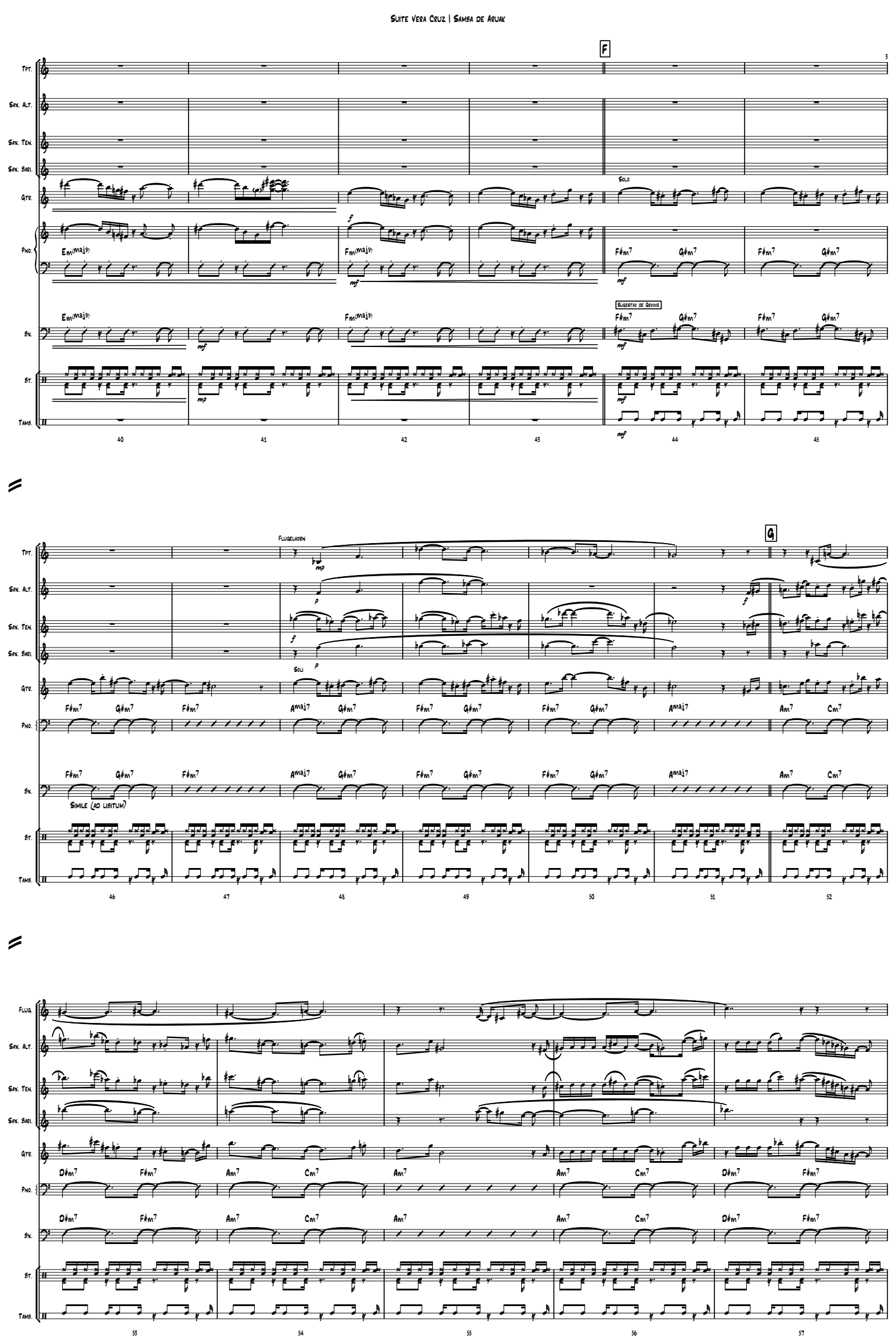

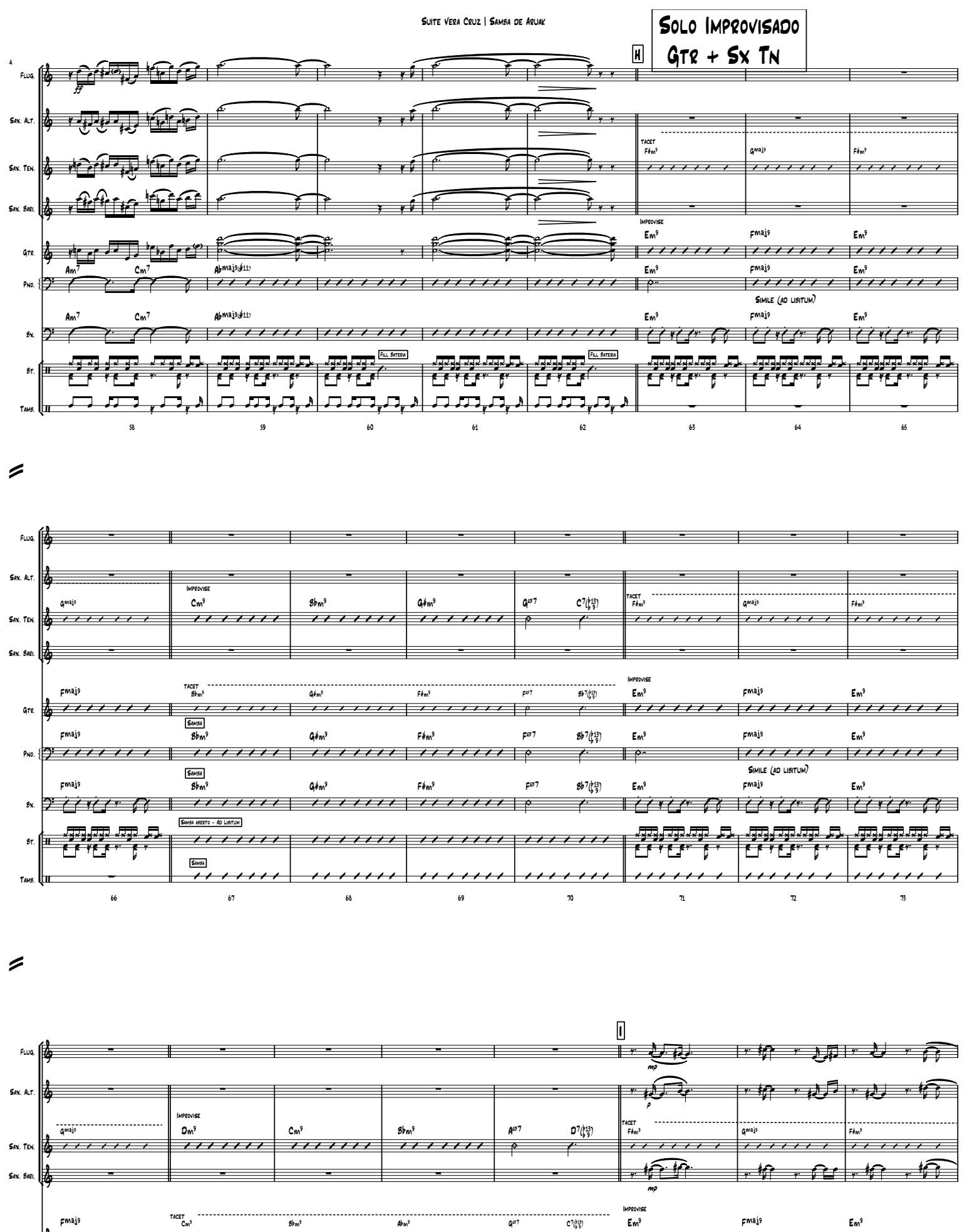

are

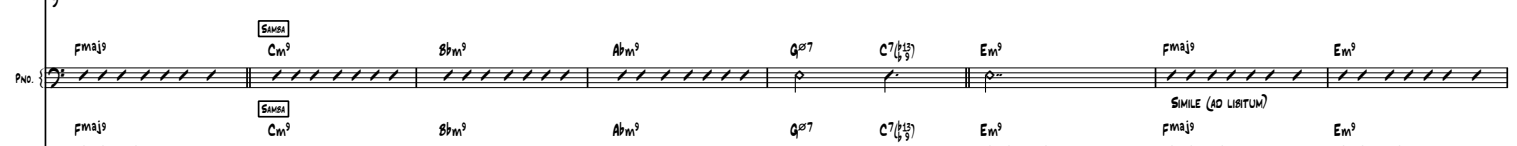

8.

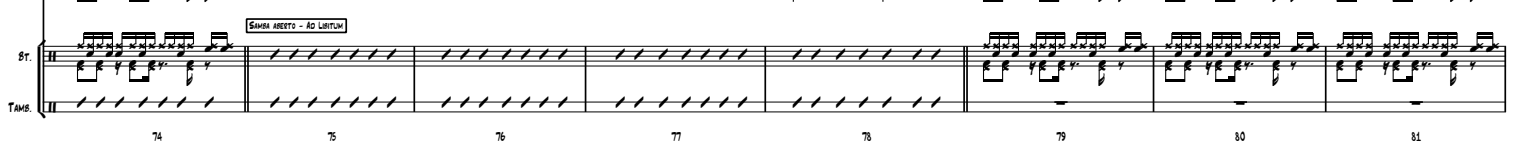



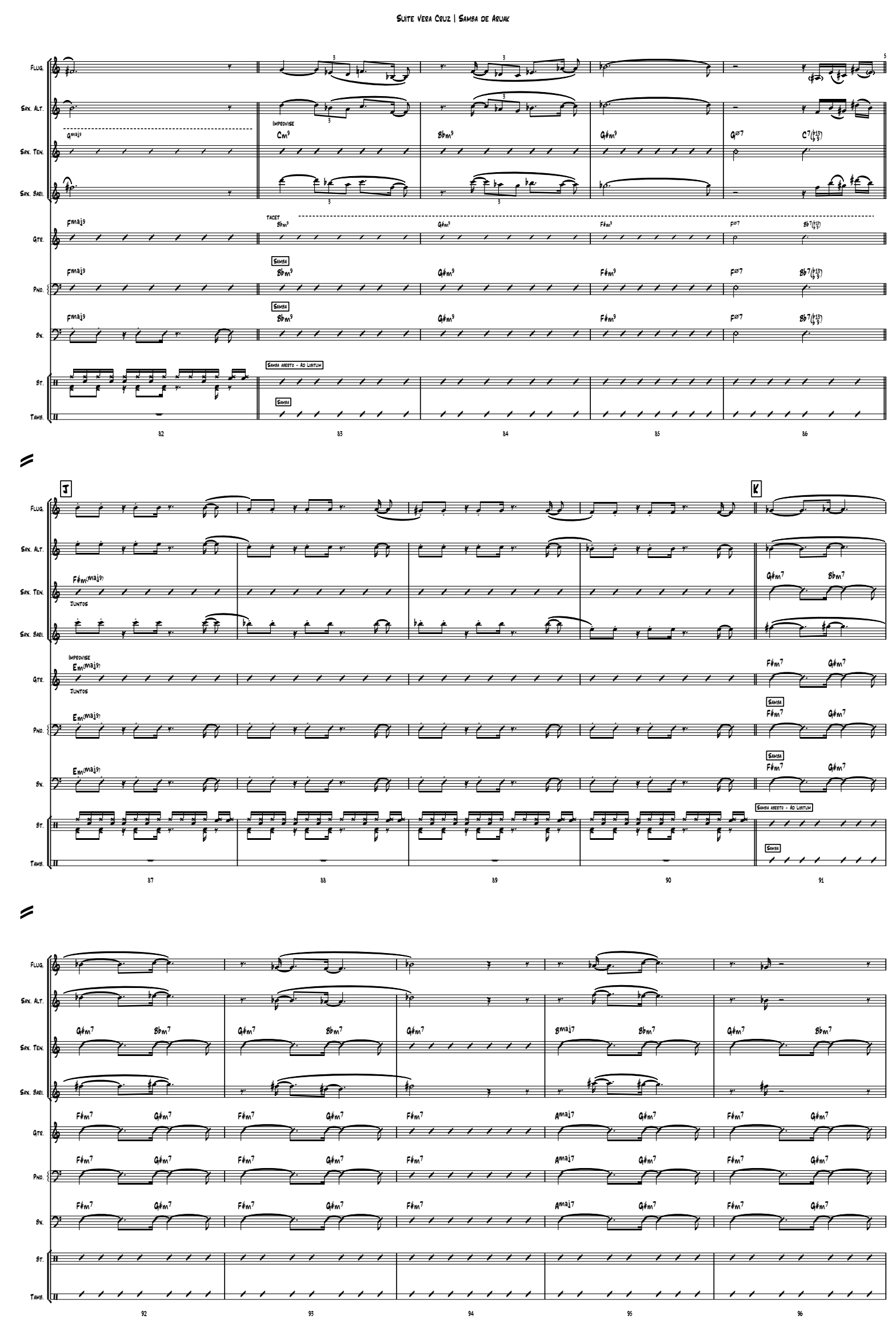

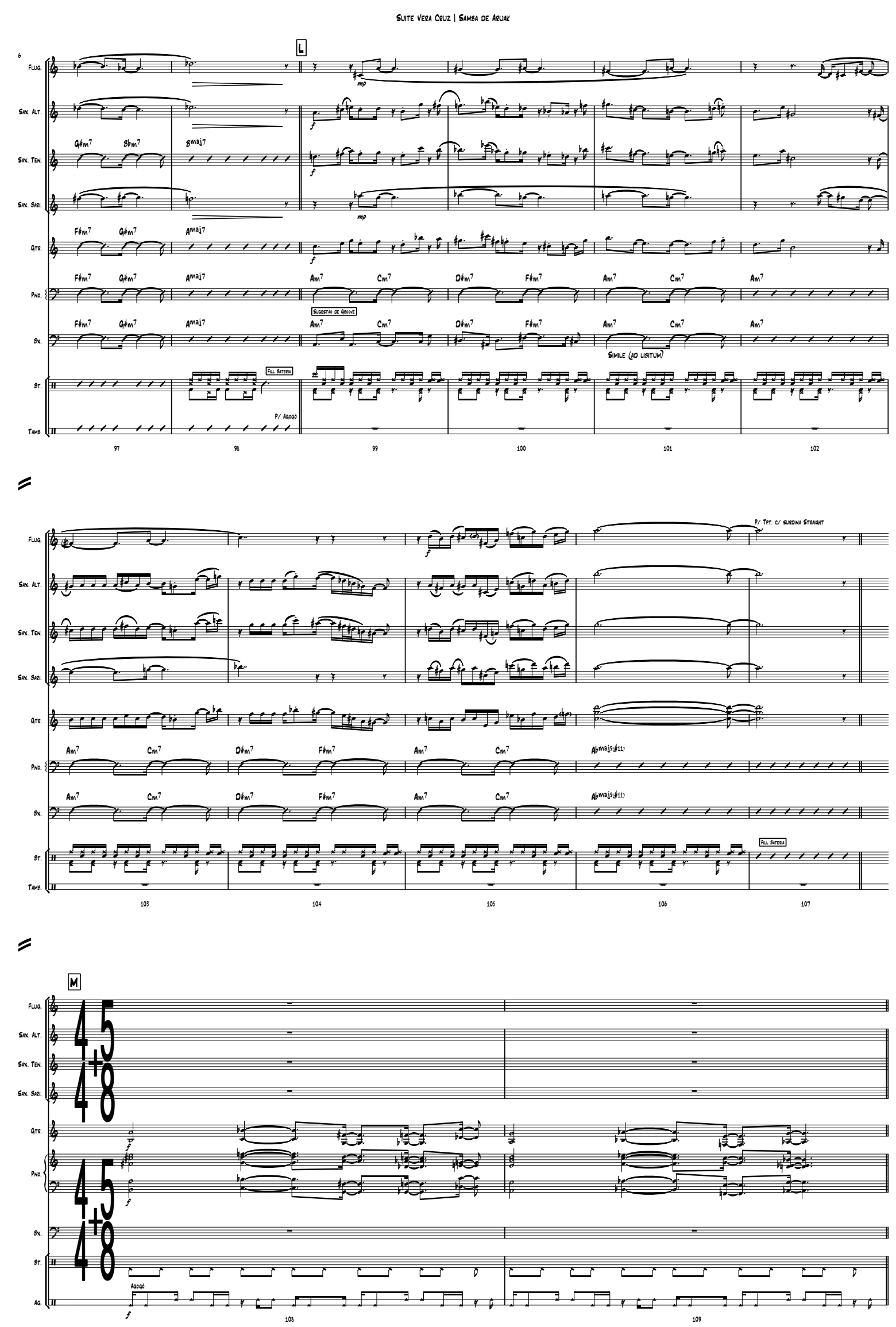

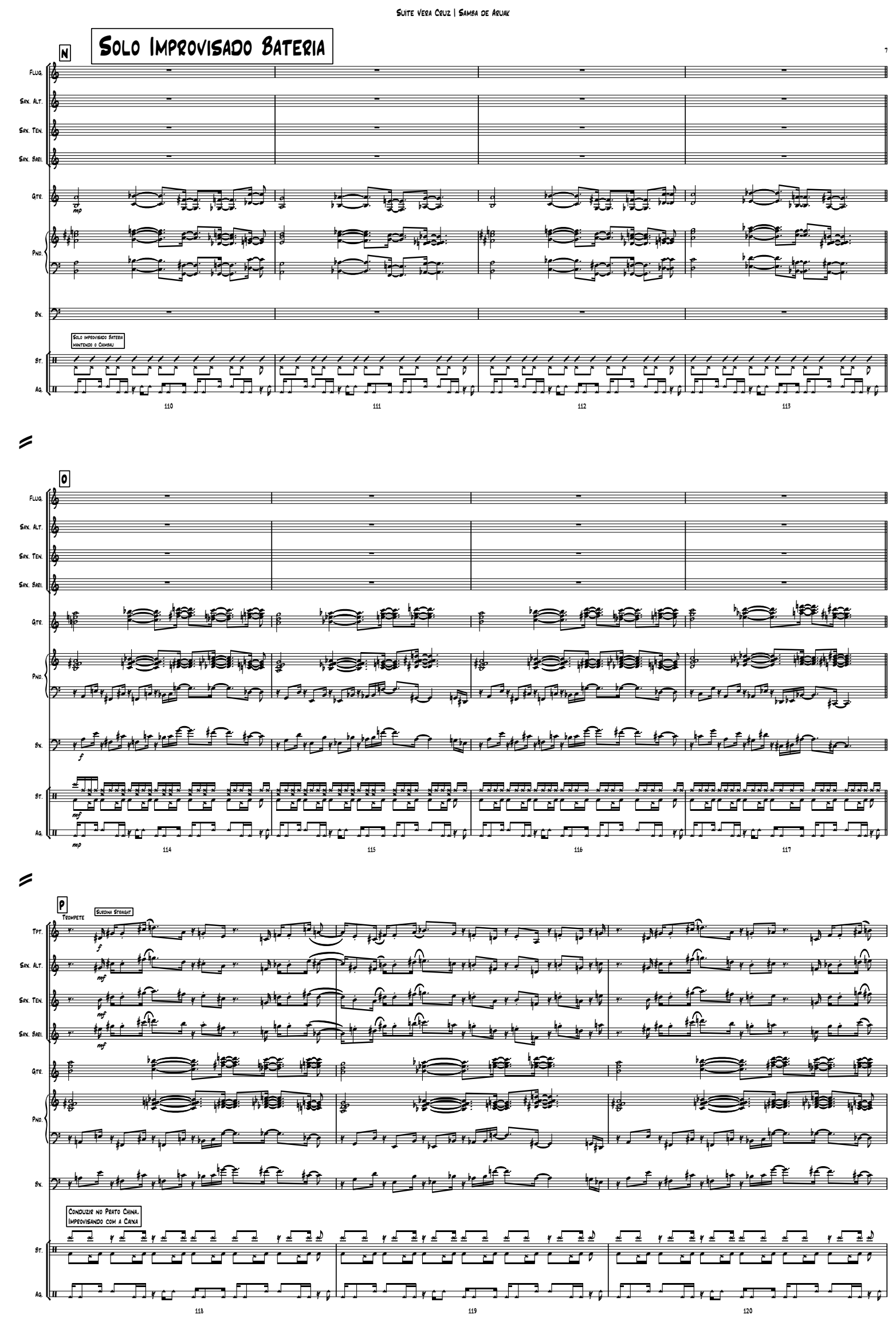
[a

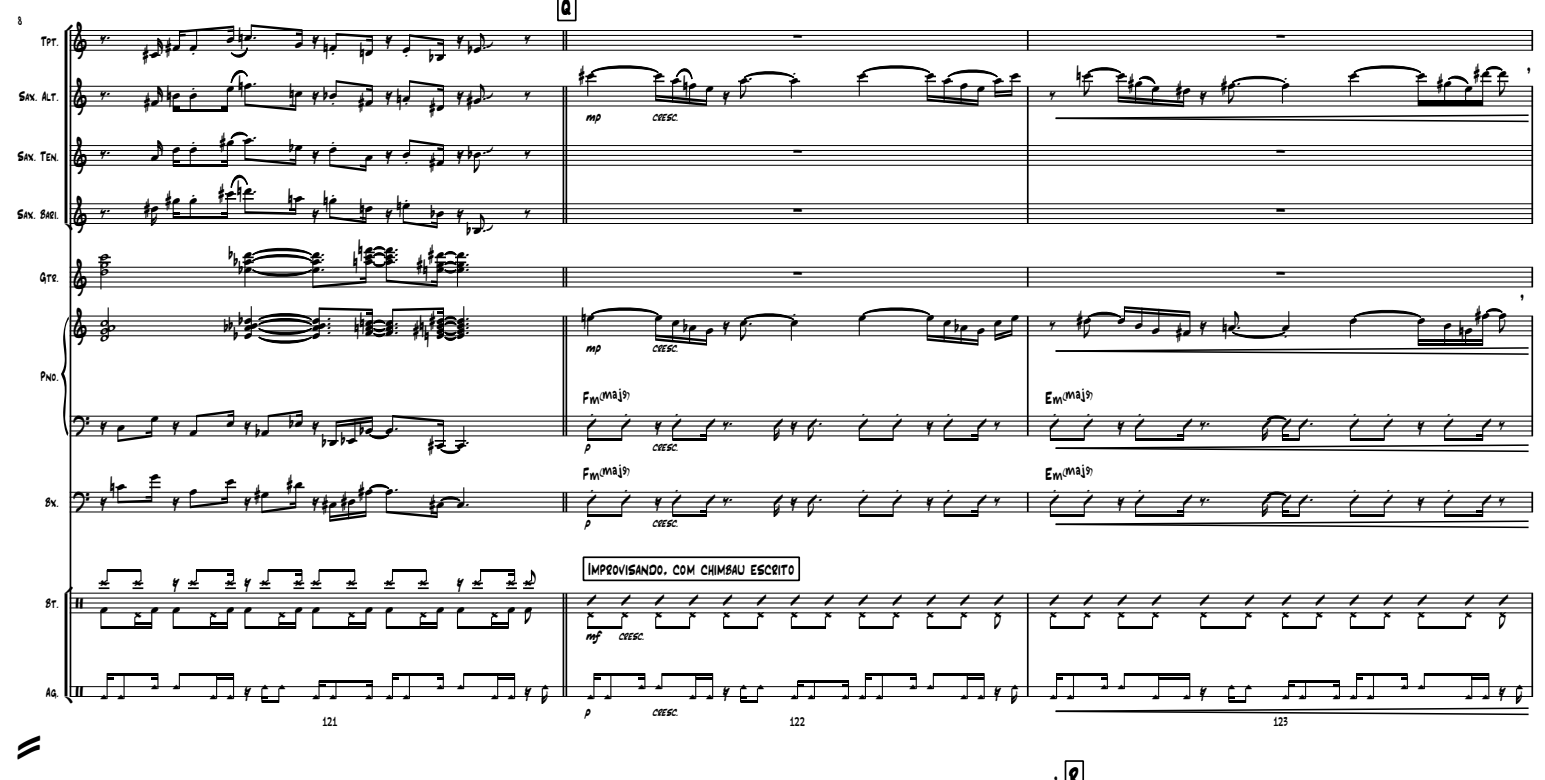

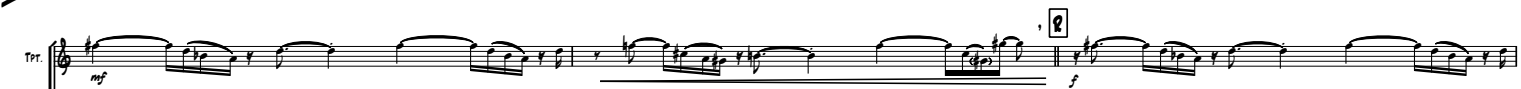
SNMan

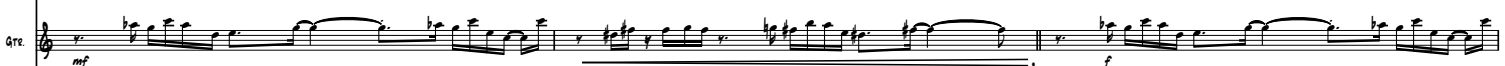
and

* w w $\left.\right|_{n}$ $=$

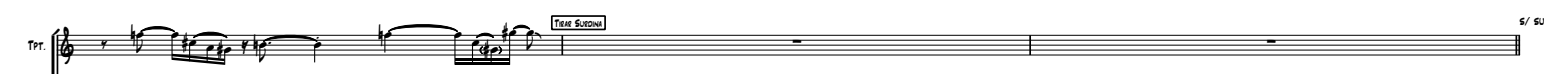

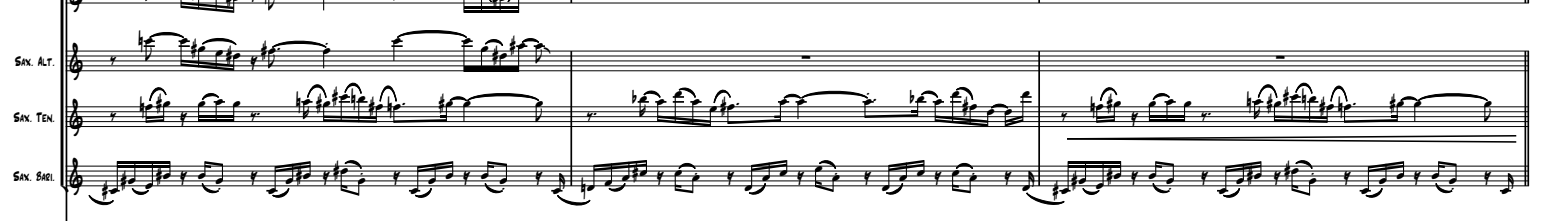

ar a (n)

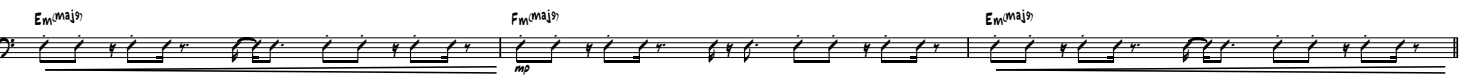
(10: 

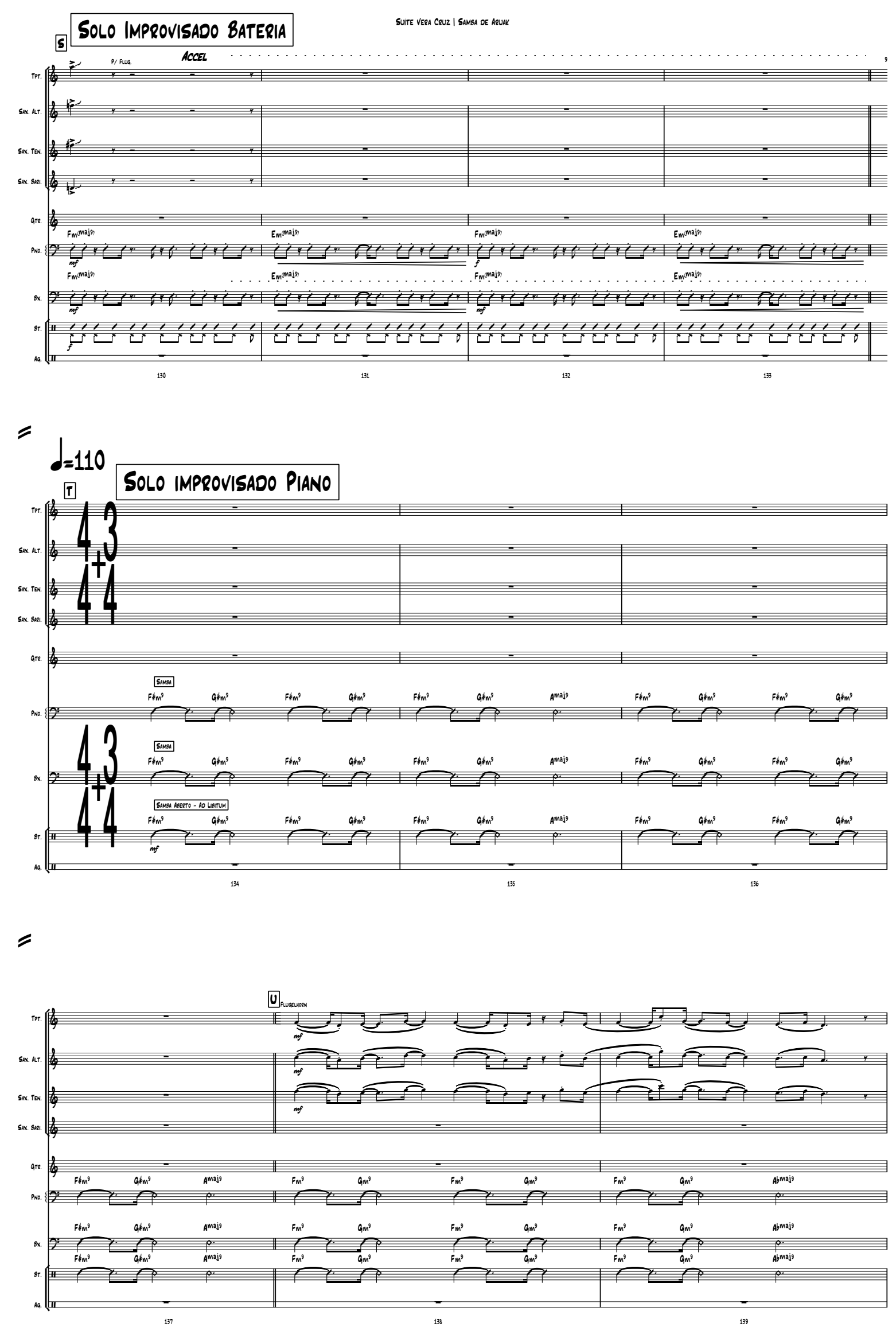

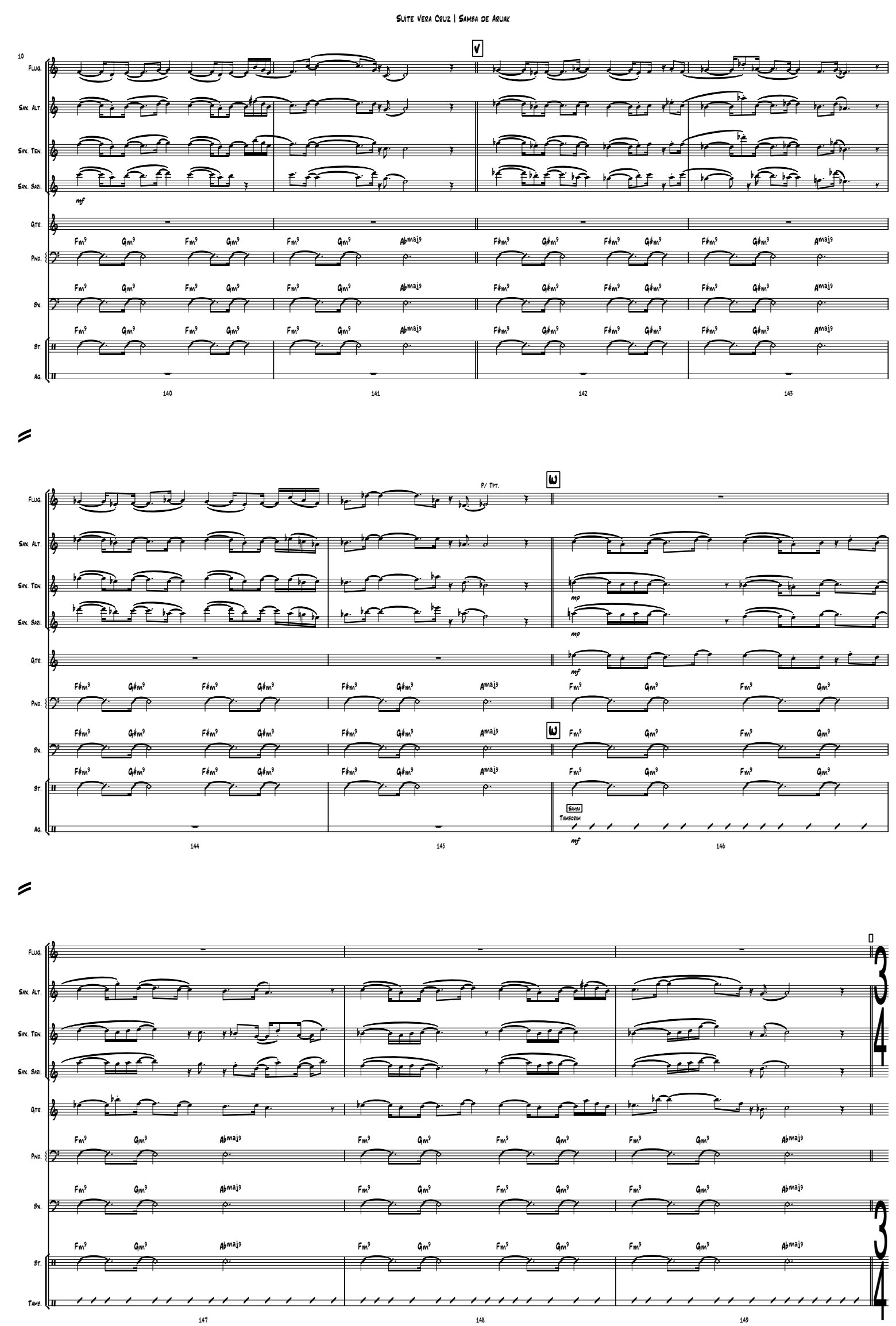

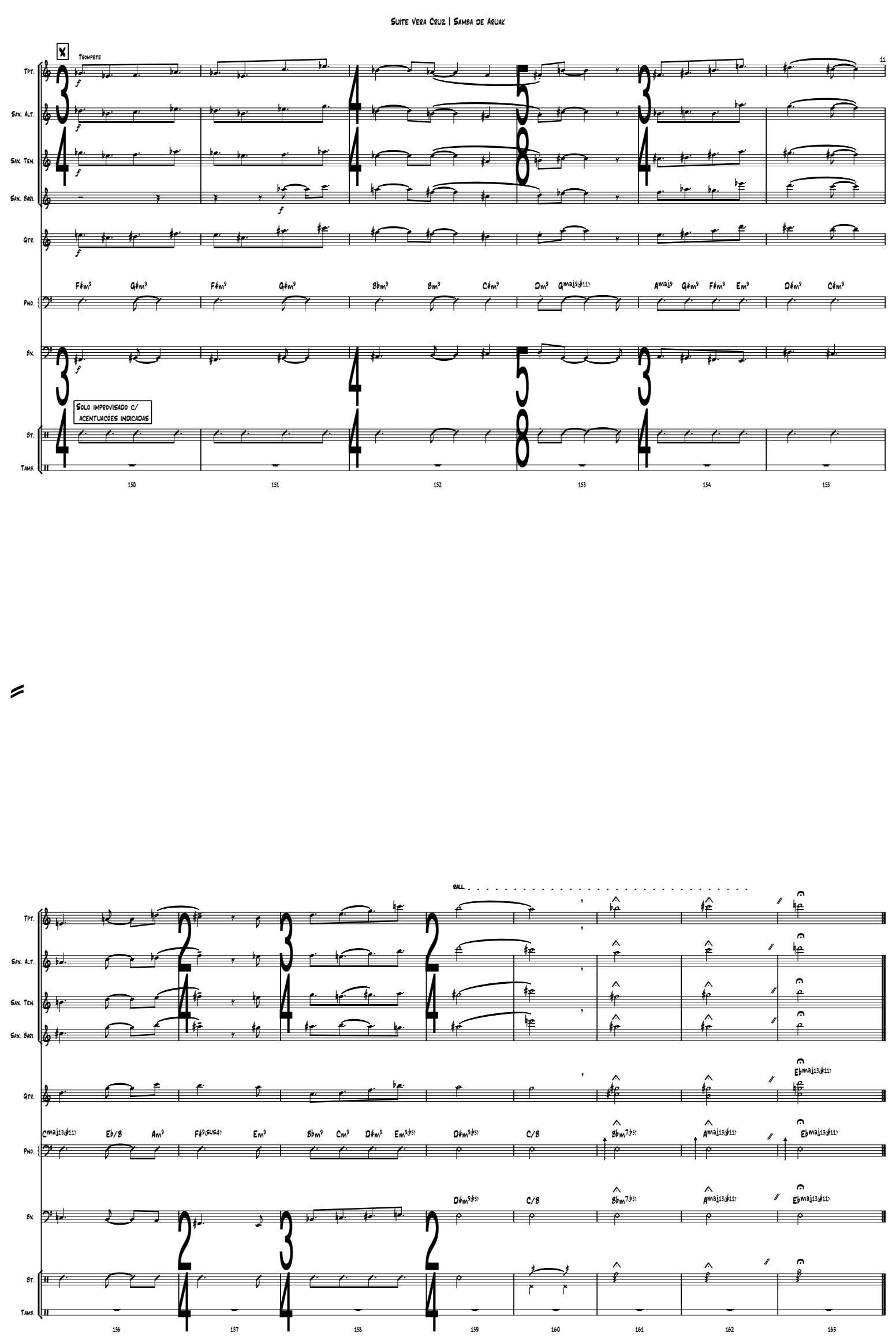
Partitura transposta

\section{SUÍTE VERA CRUL:
II-MARACATU DE ENGENHO}

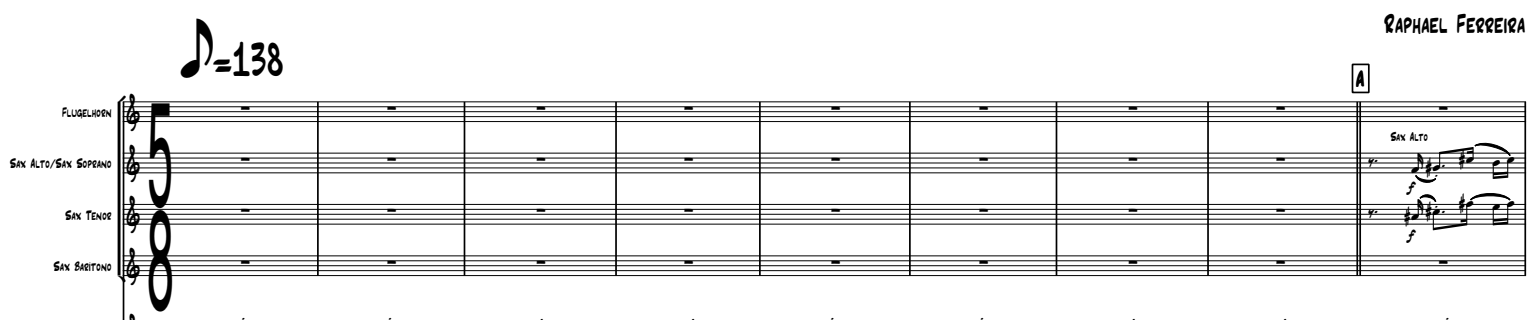

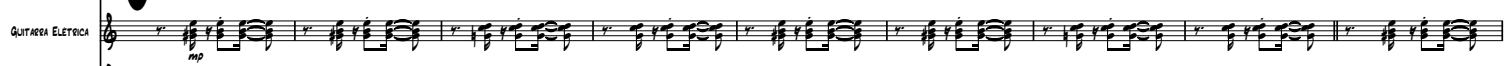
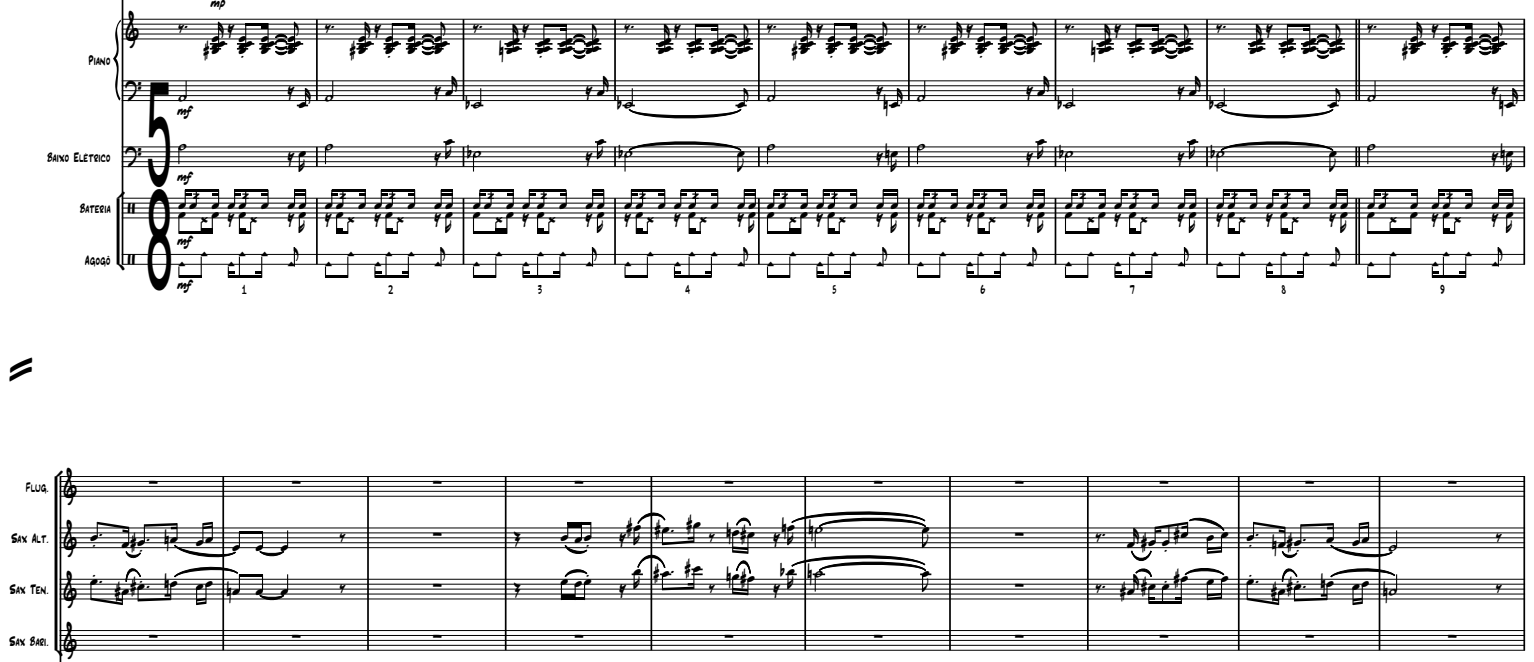

4r (4) $\therefore$ (n)

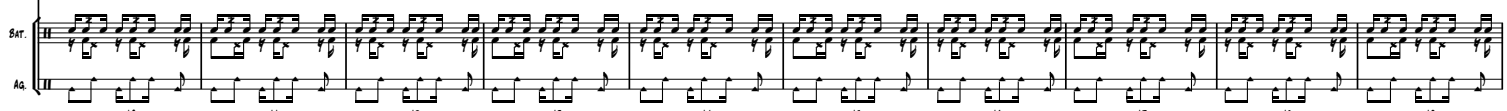

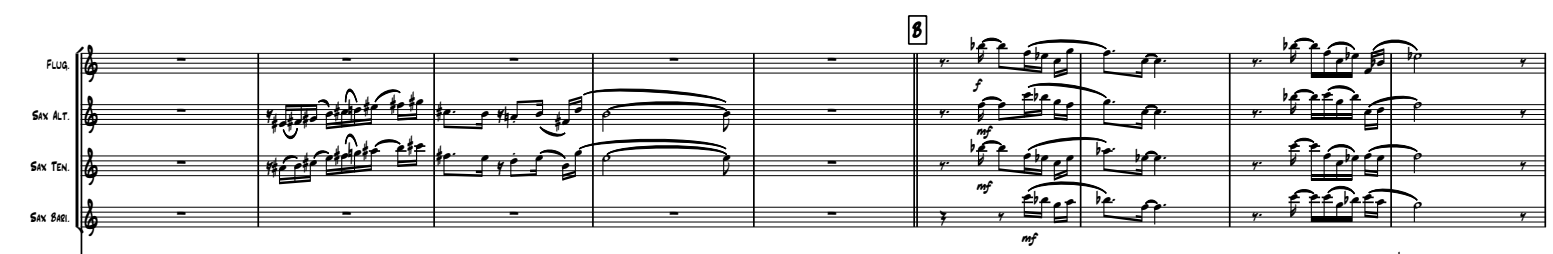

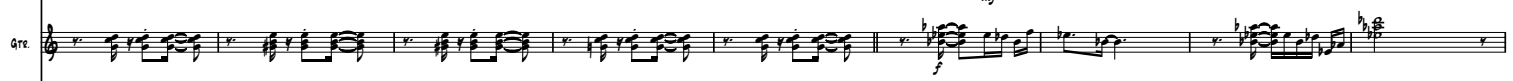

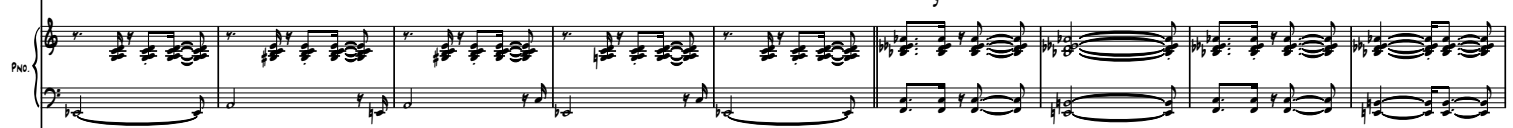

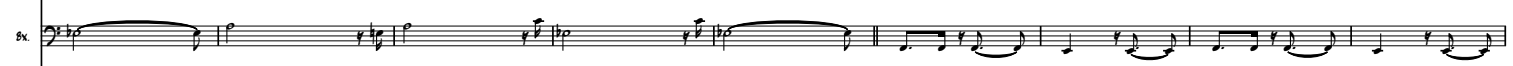
(II) 


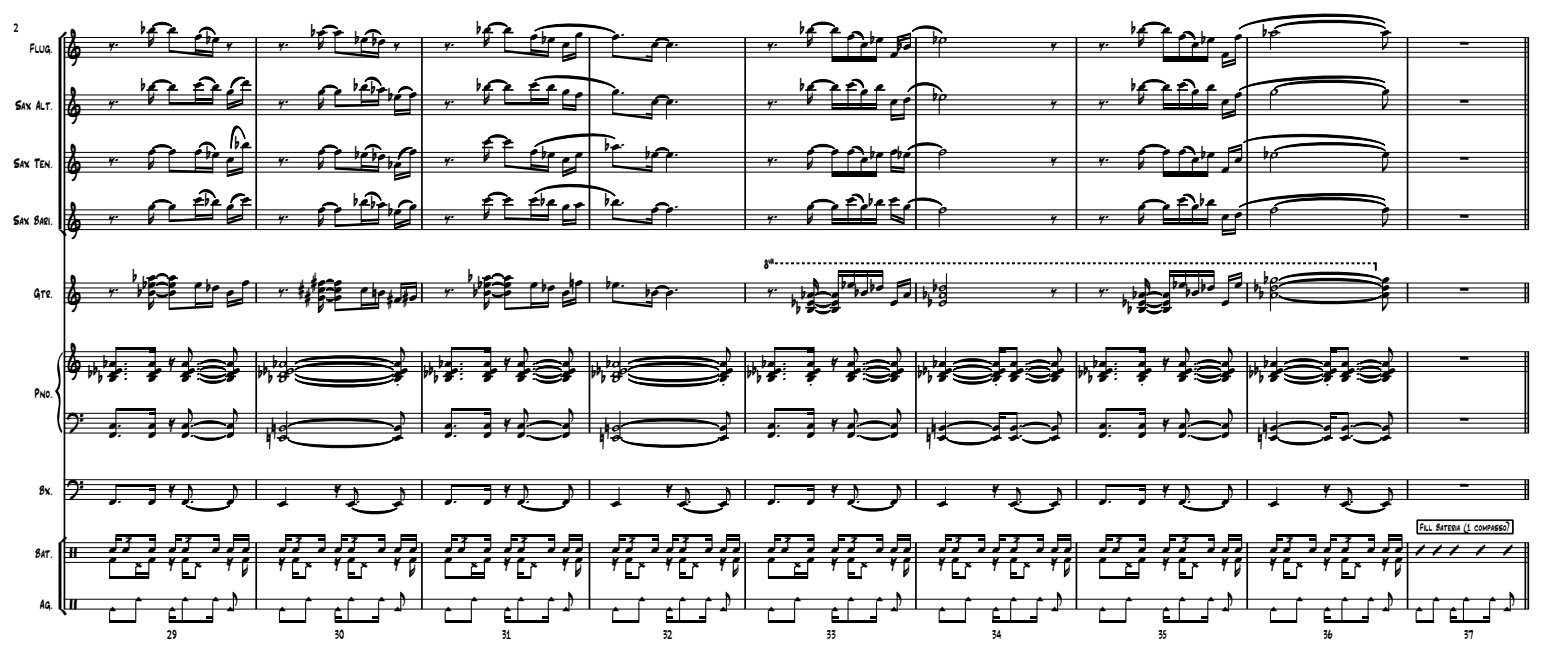

$=$
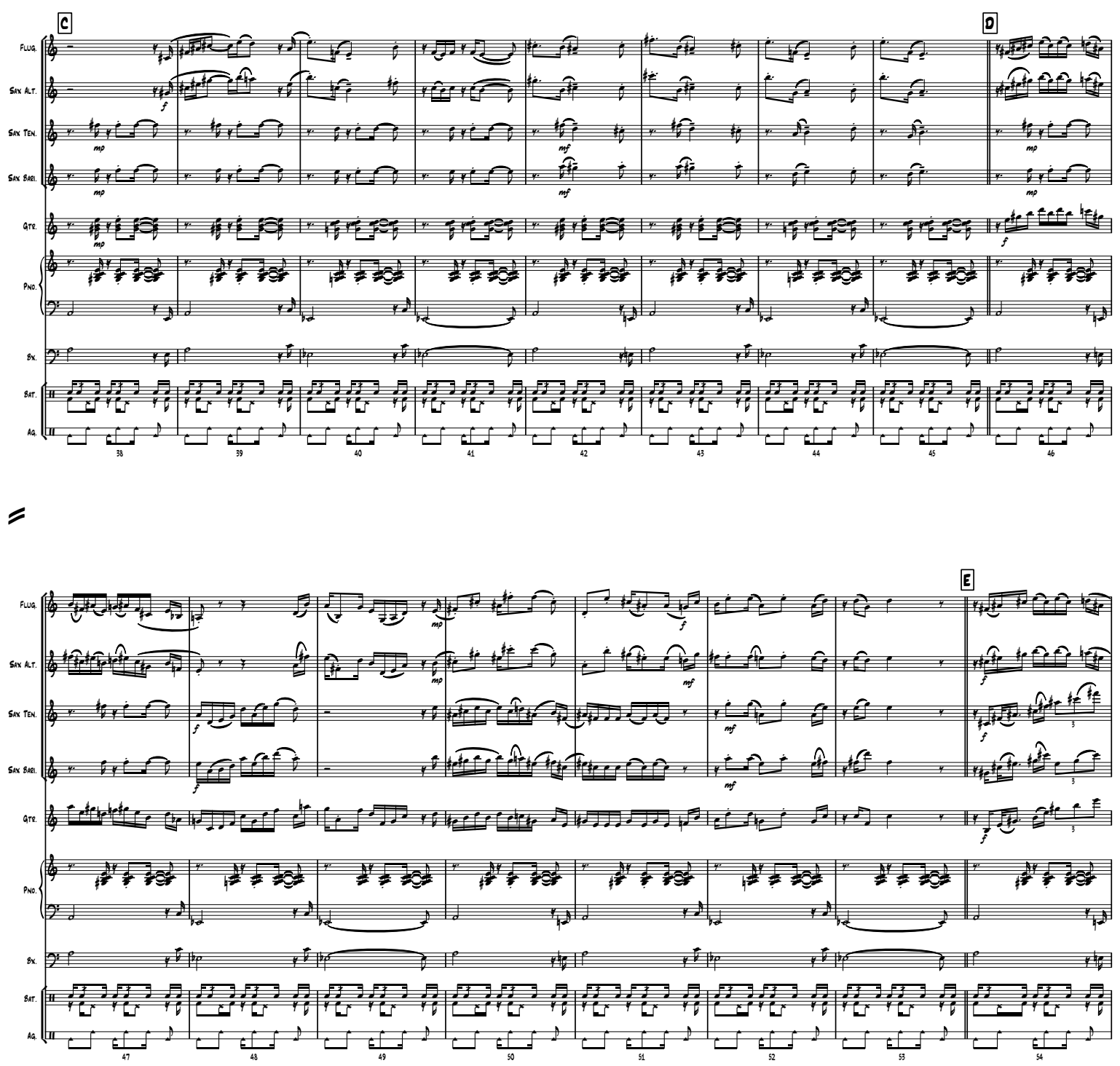

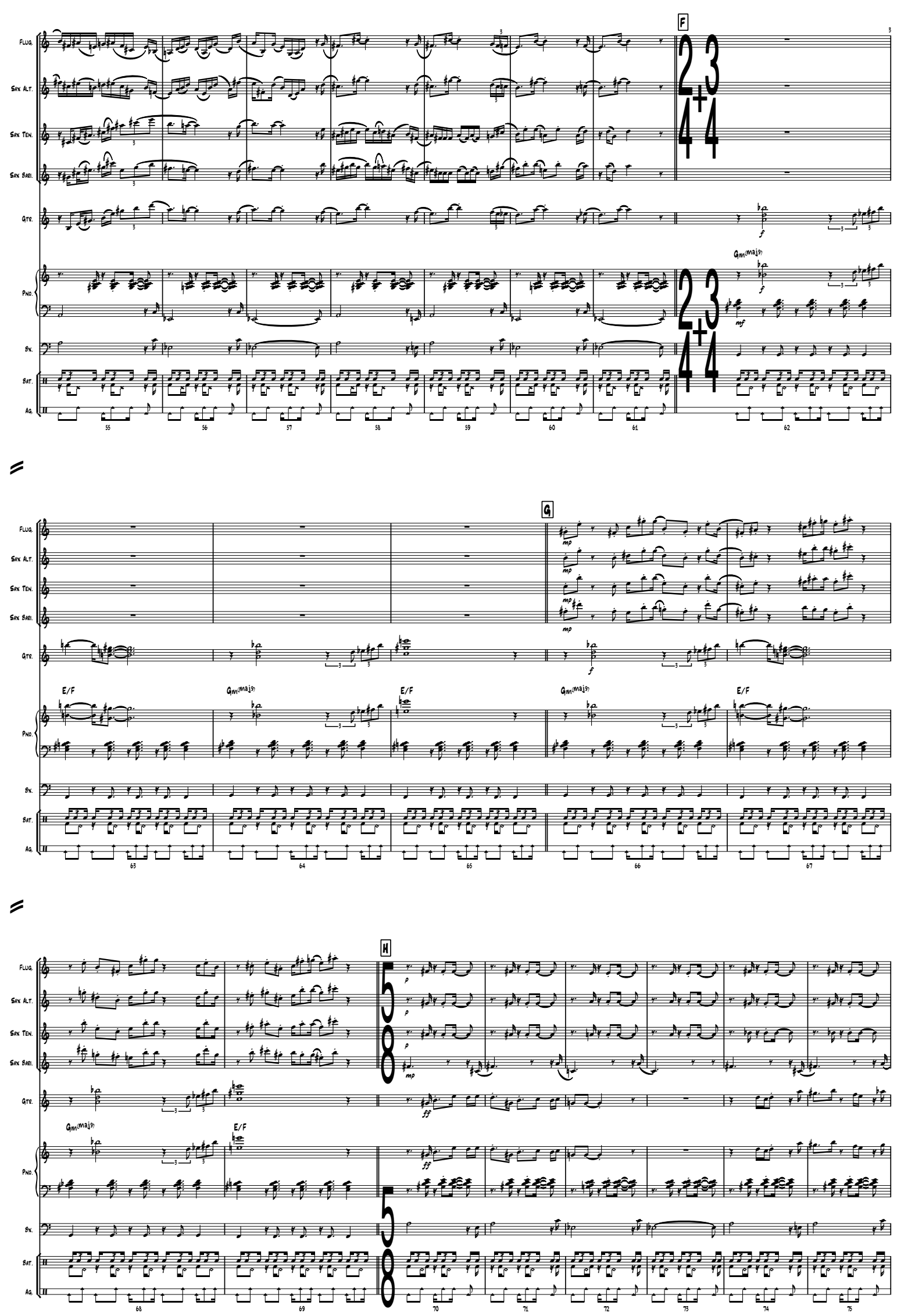


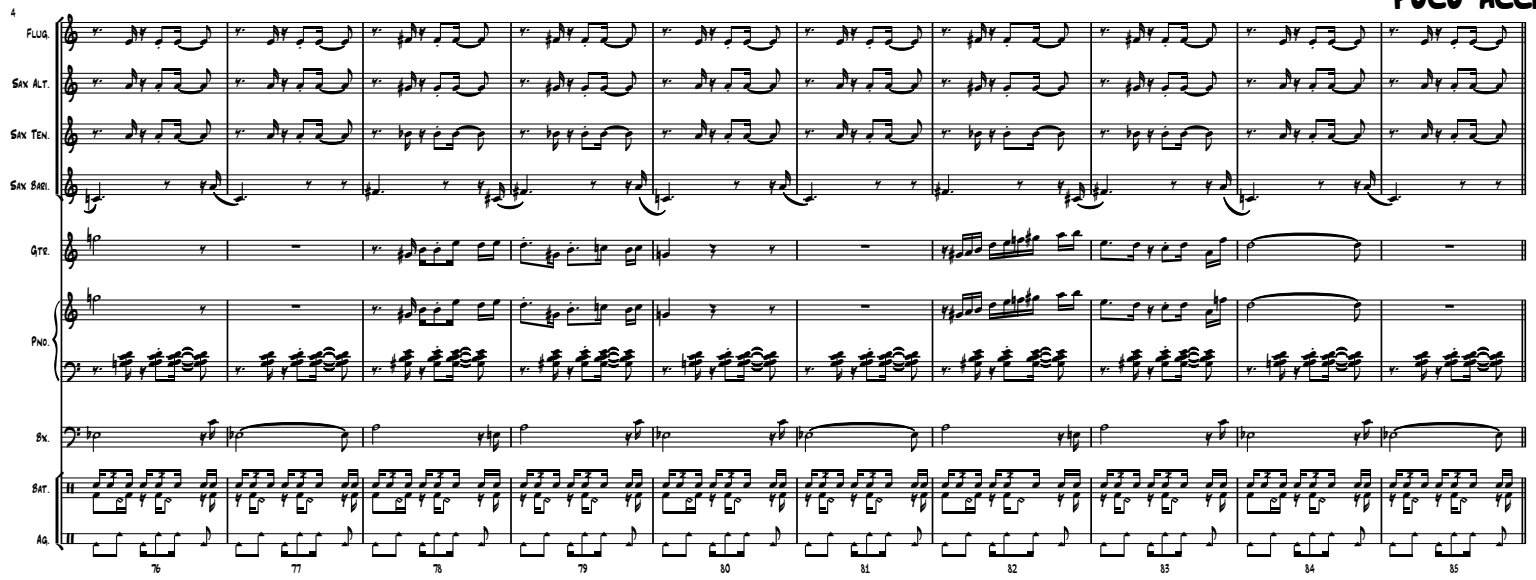

$$
\text { (1) }
$$

$=$

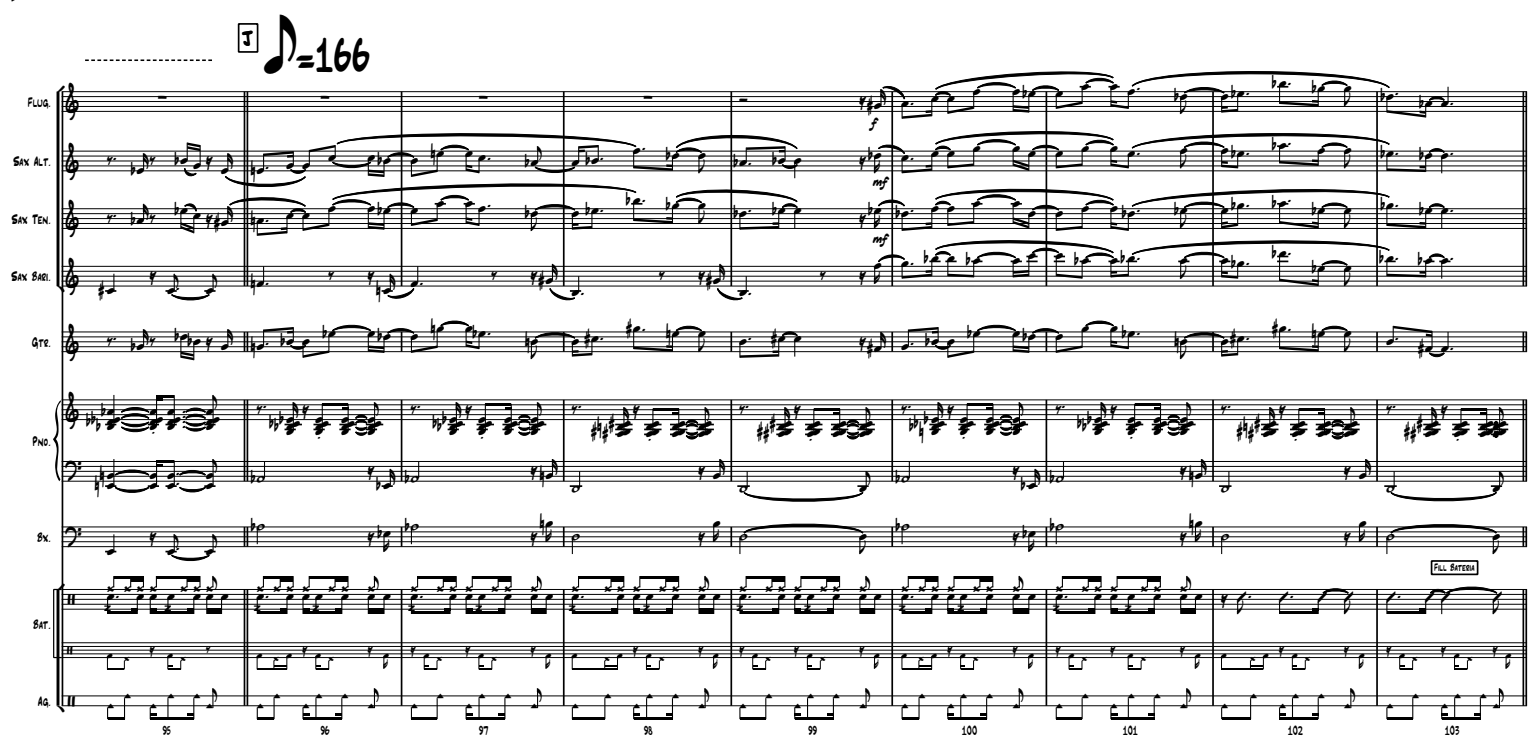




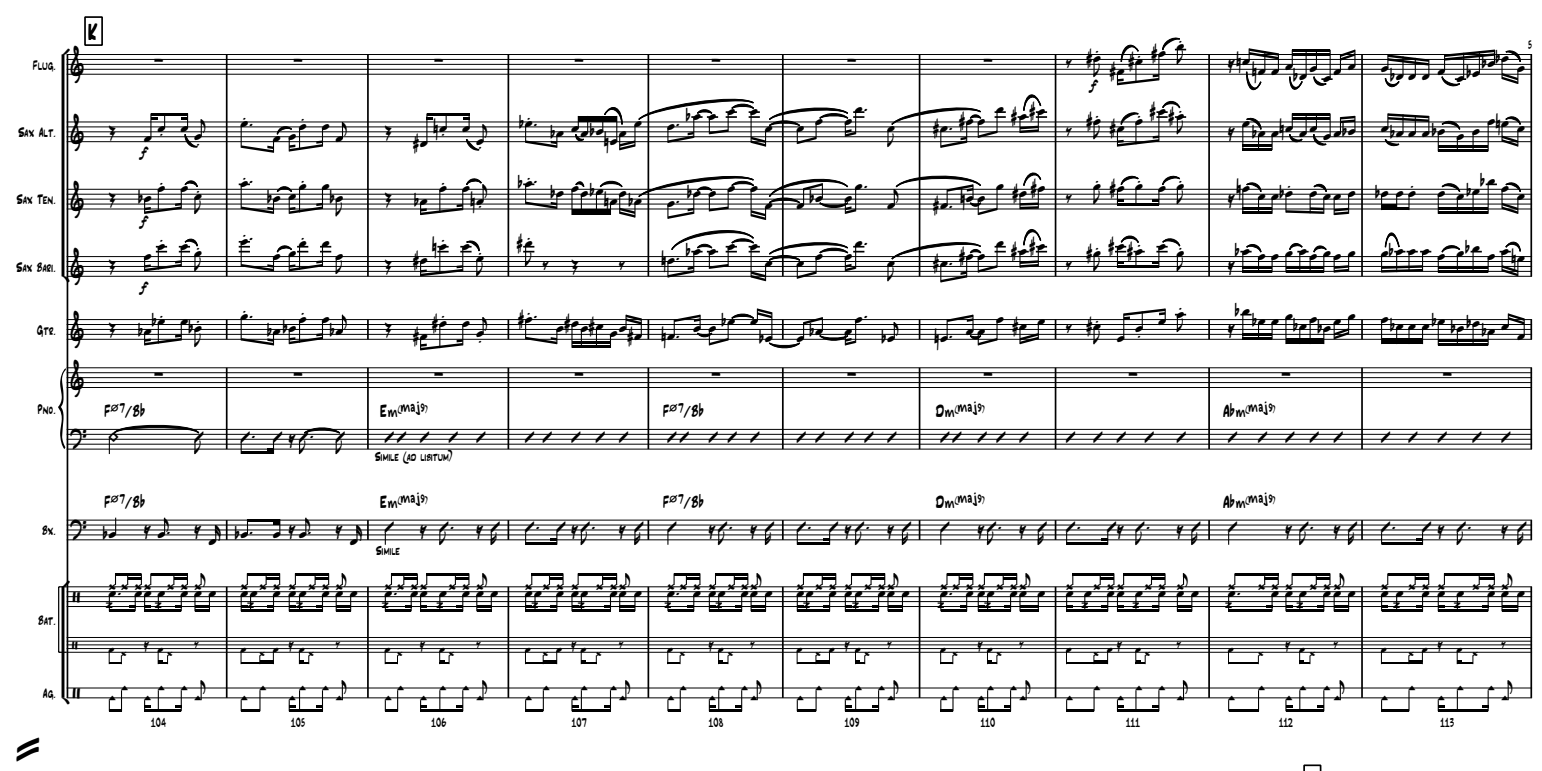

(1)

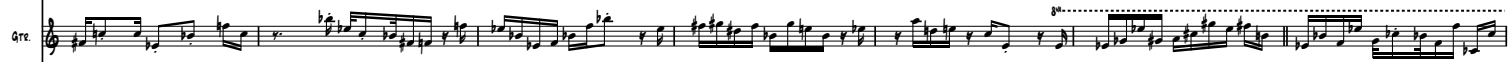
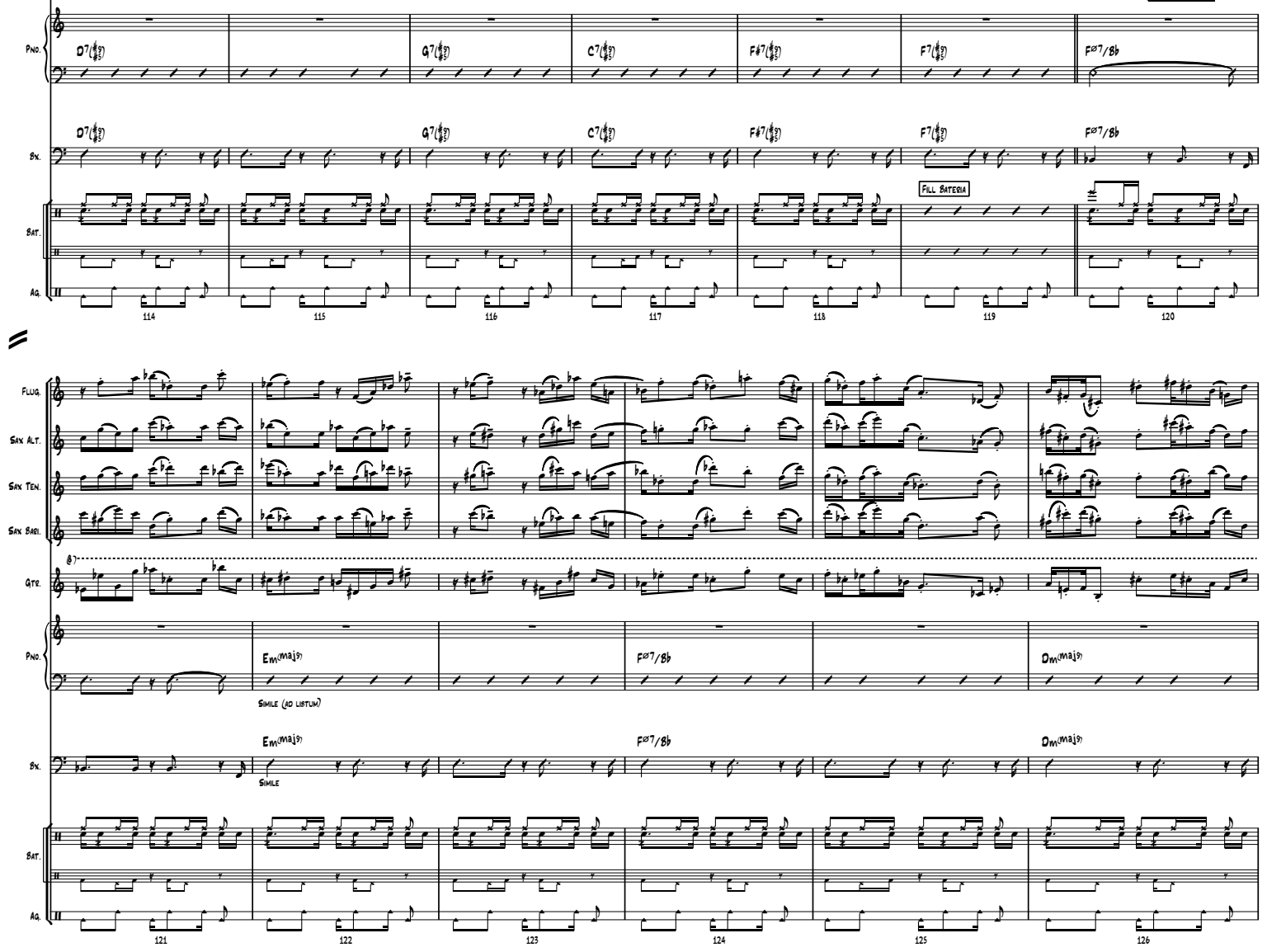

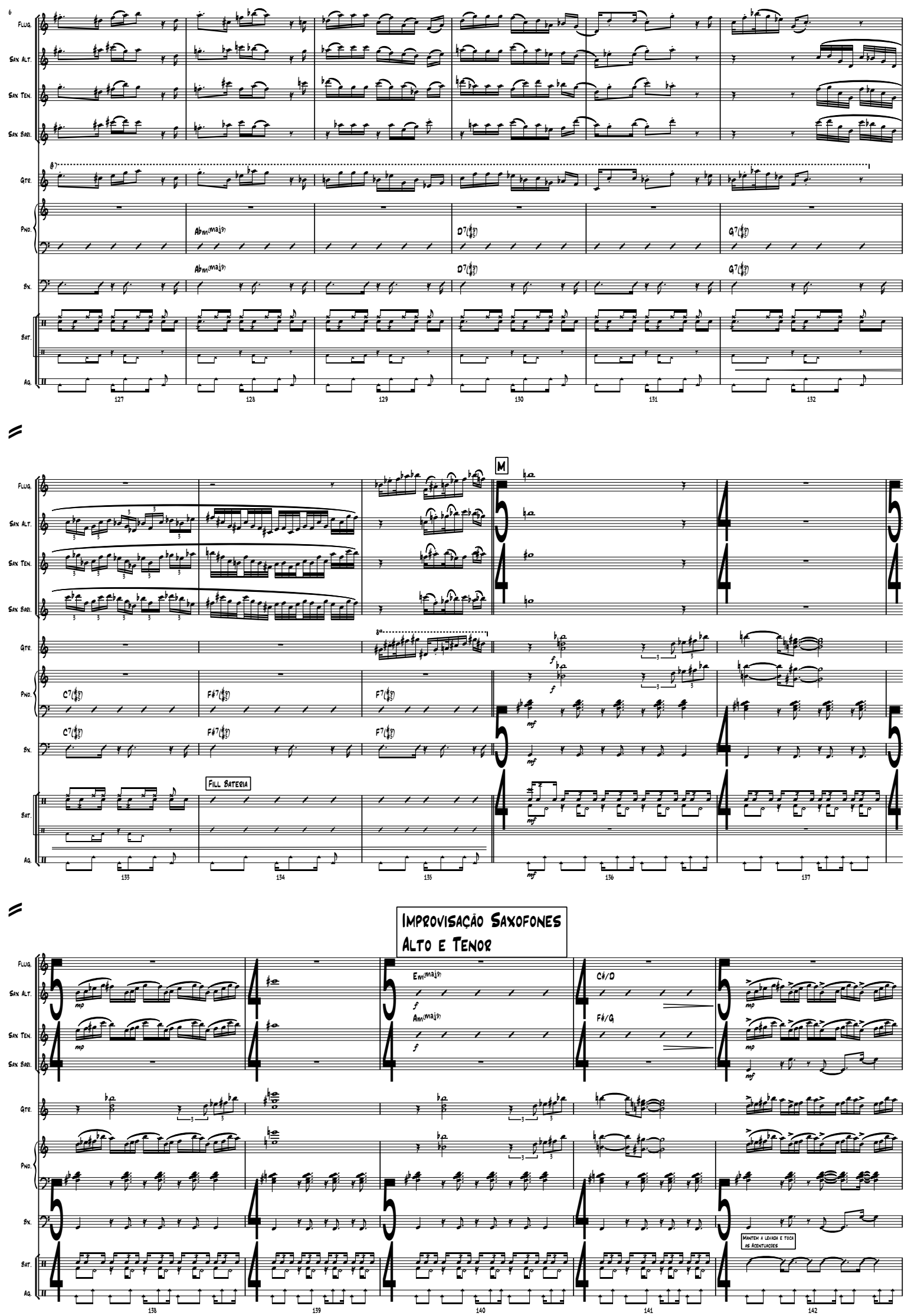

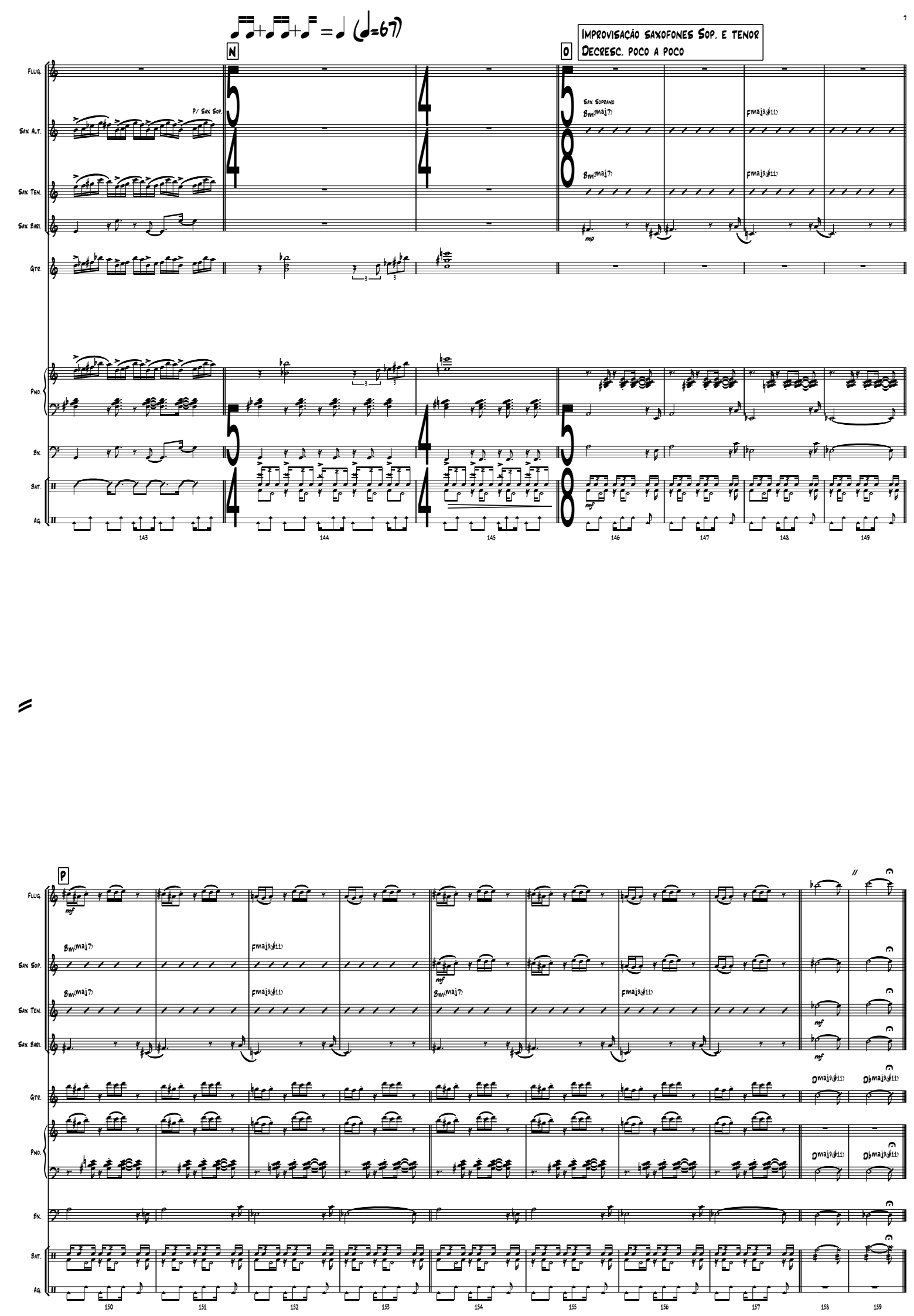

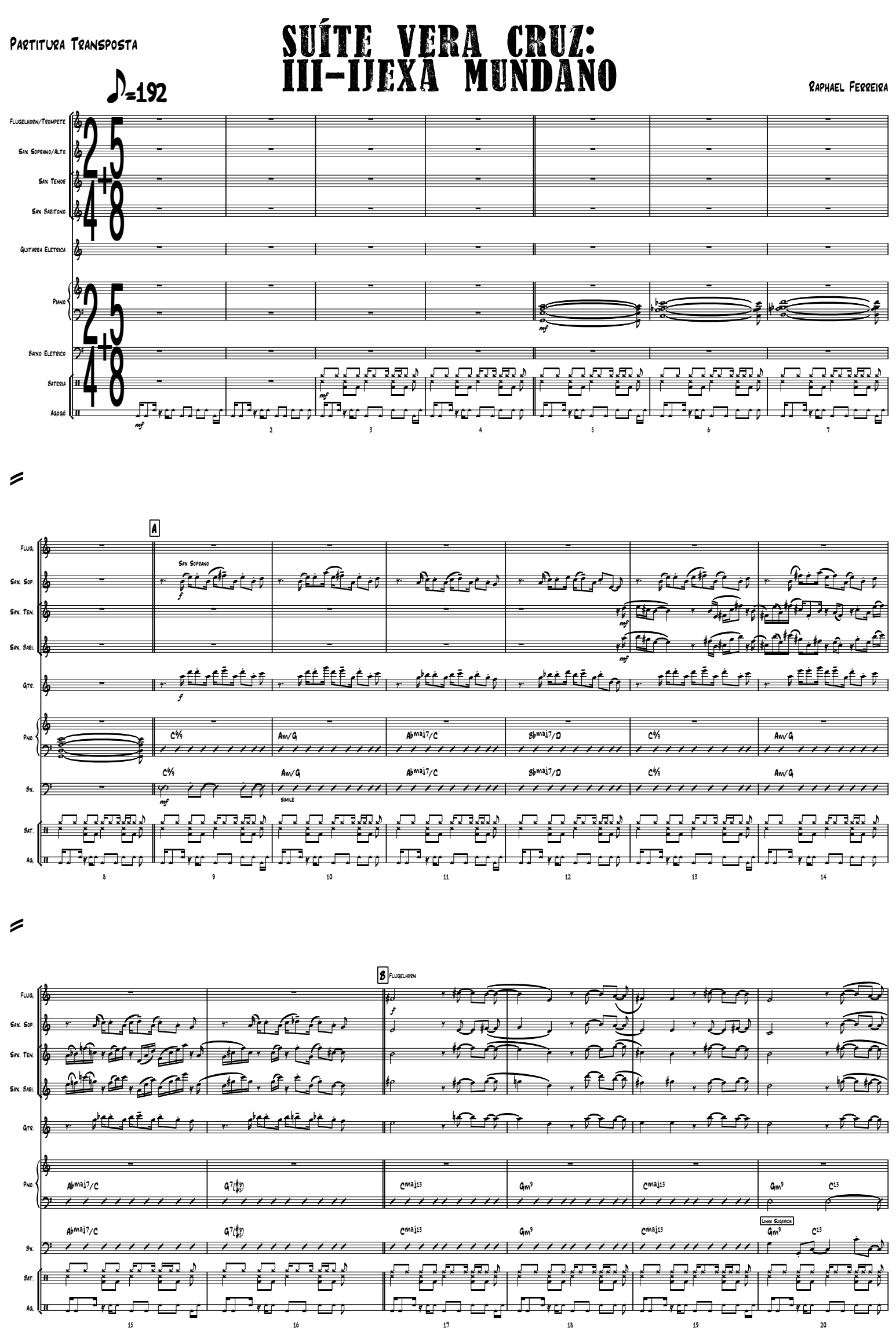


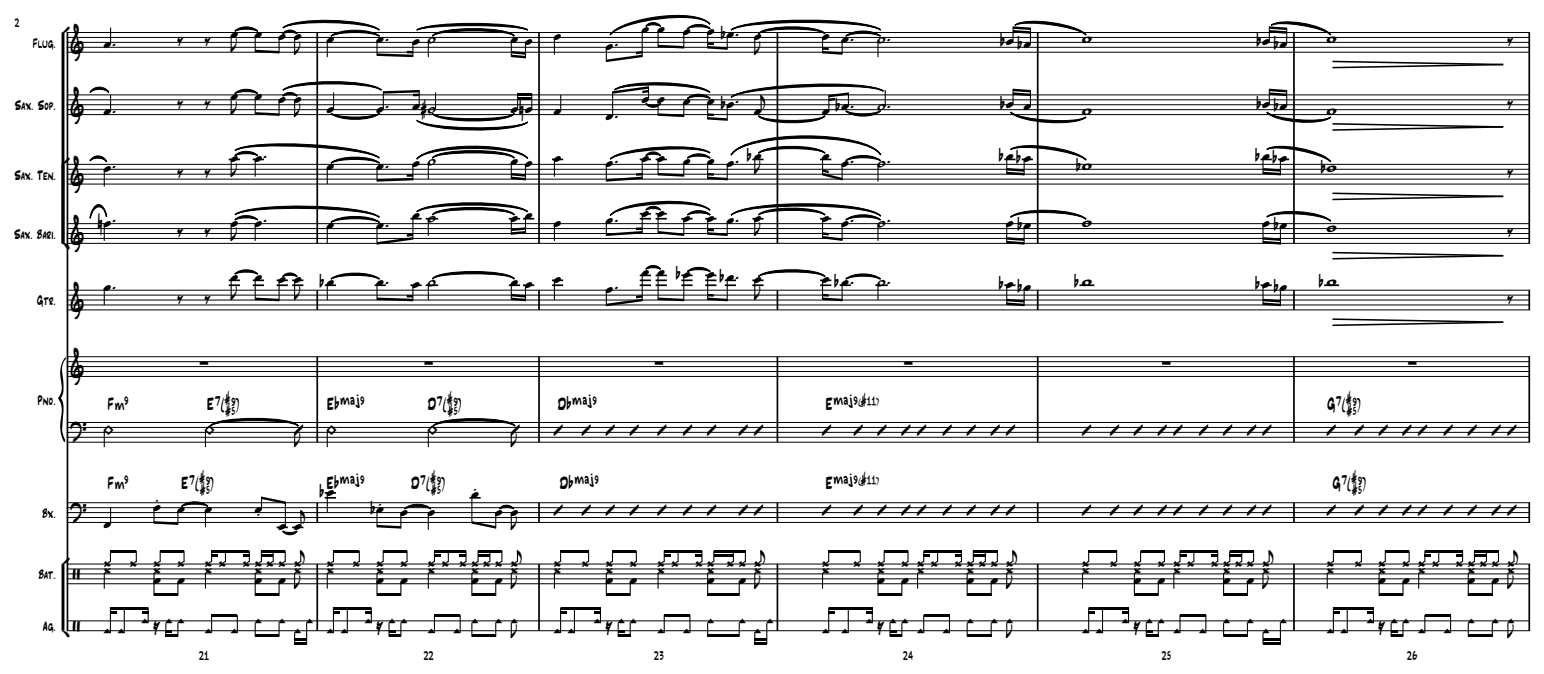

c

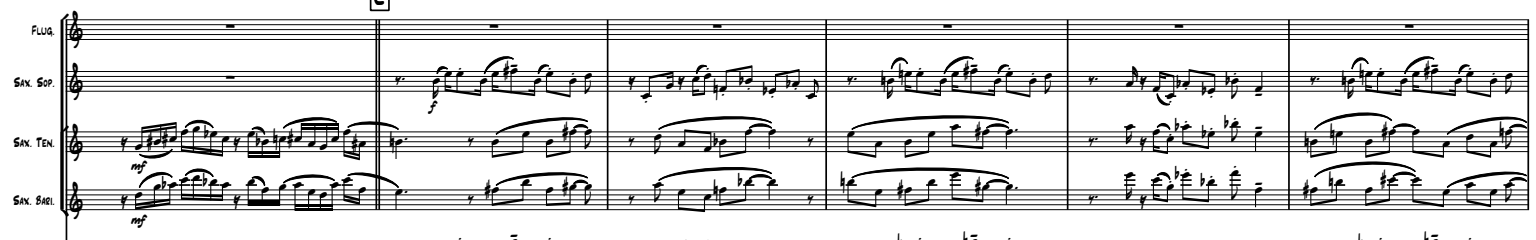

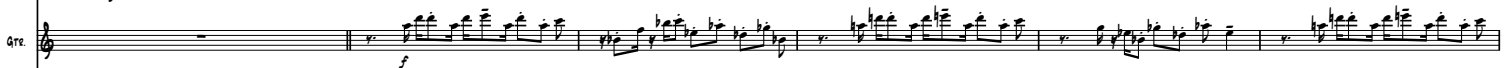

mon

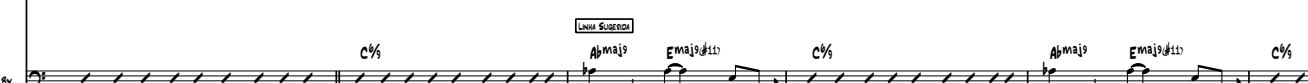

* (II)

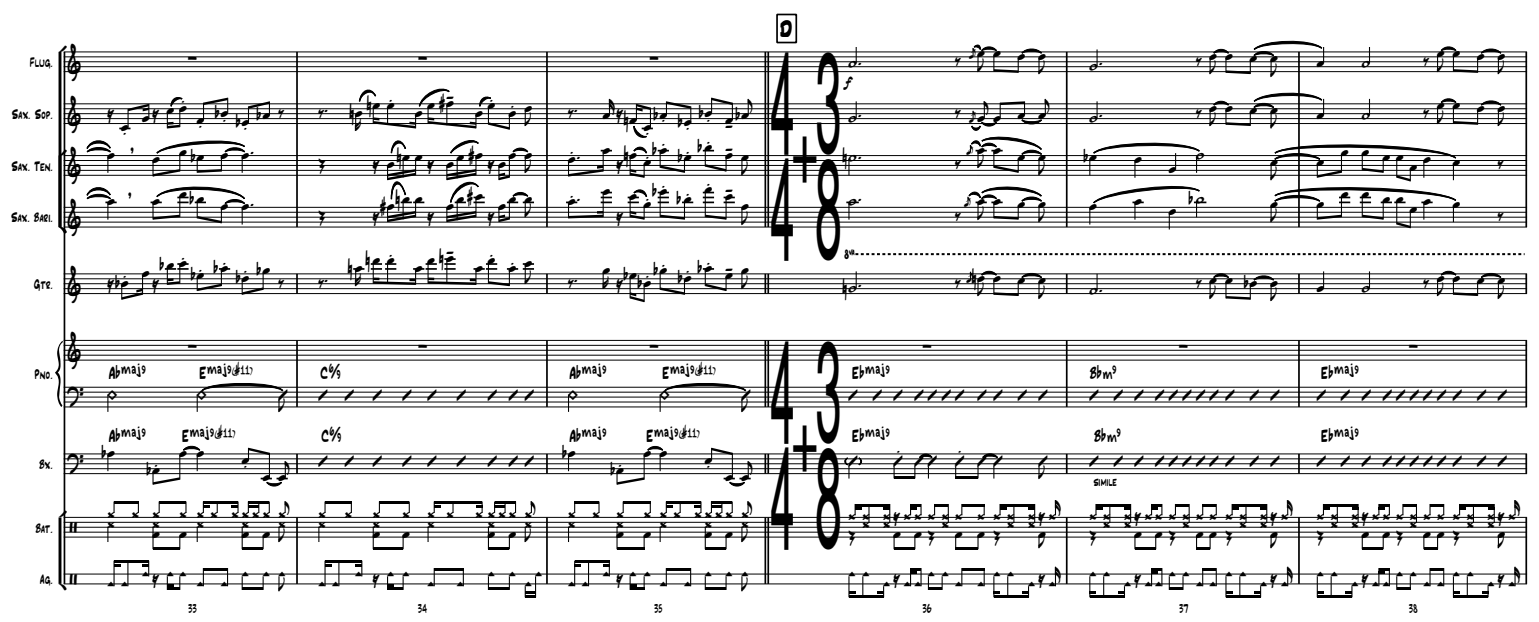



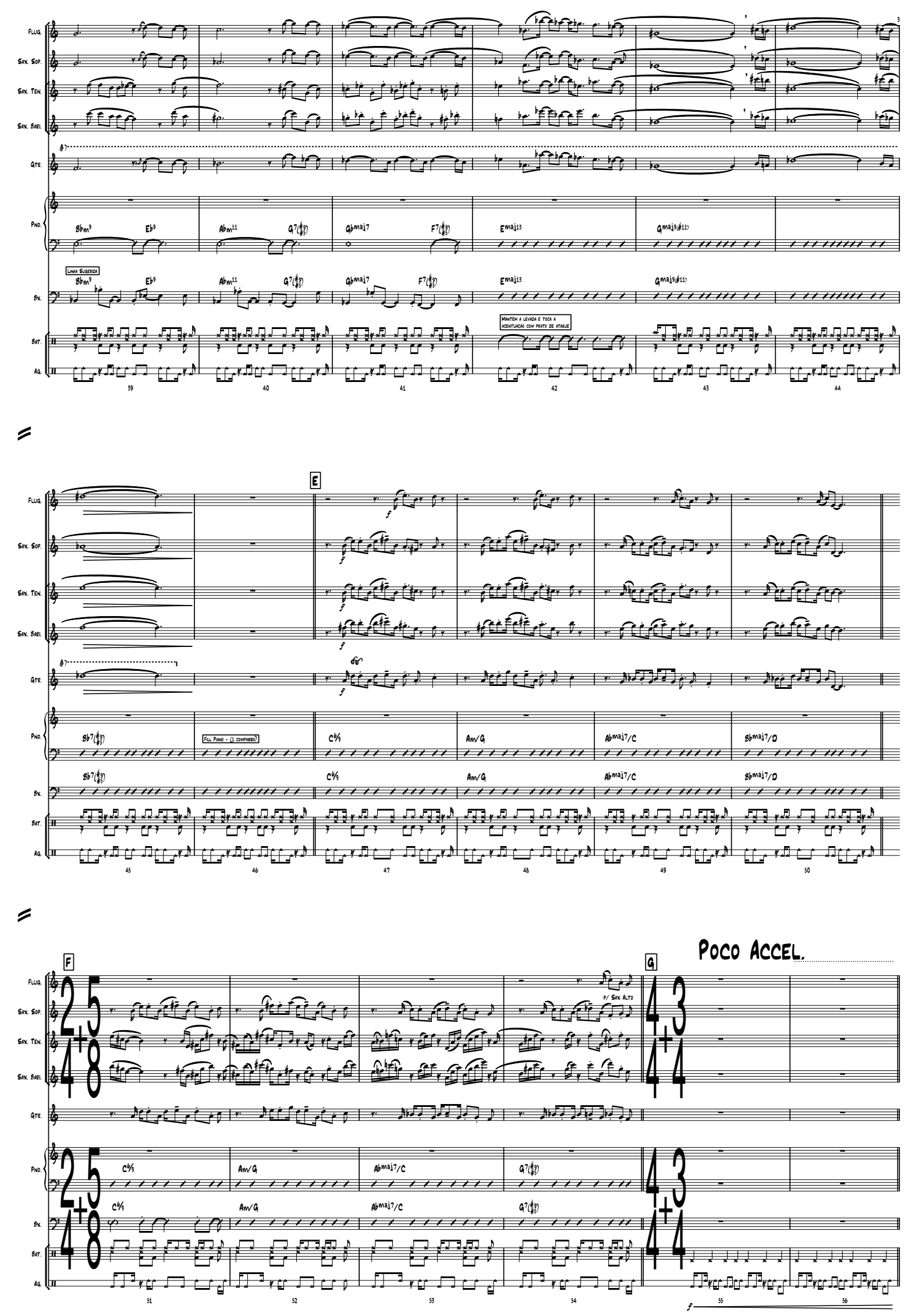

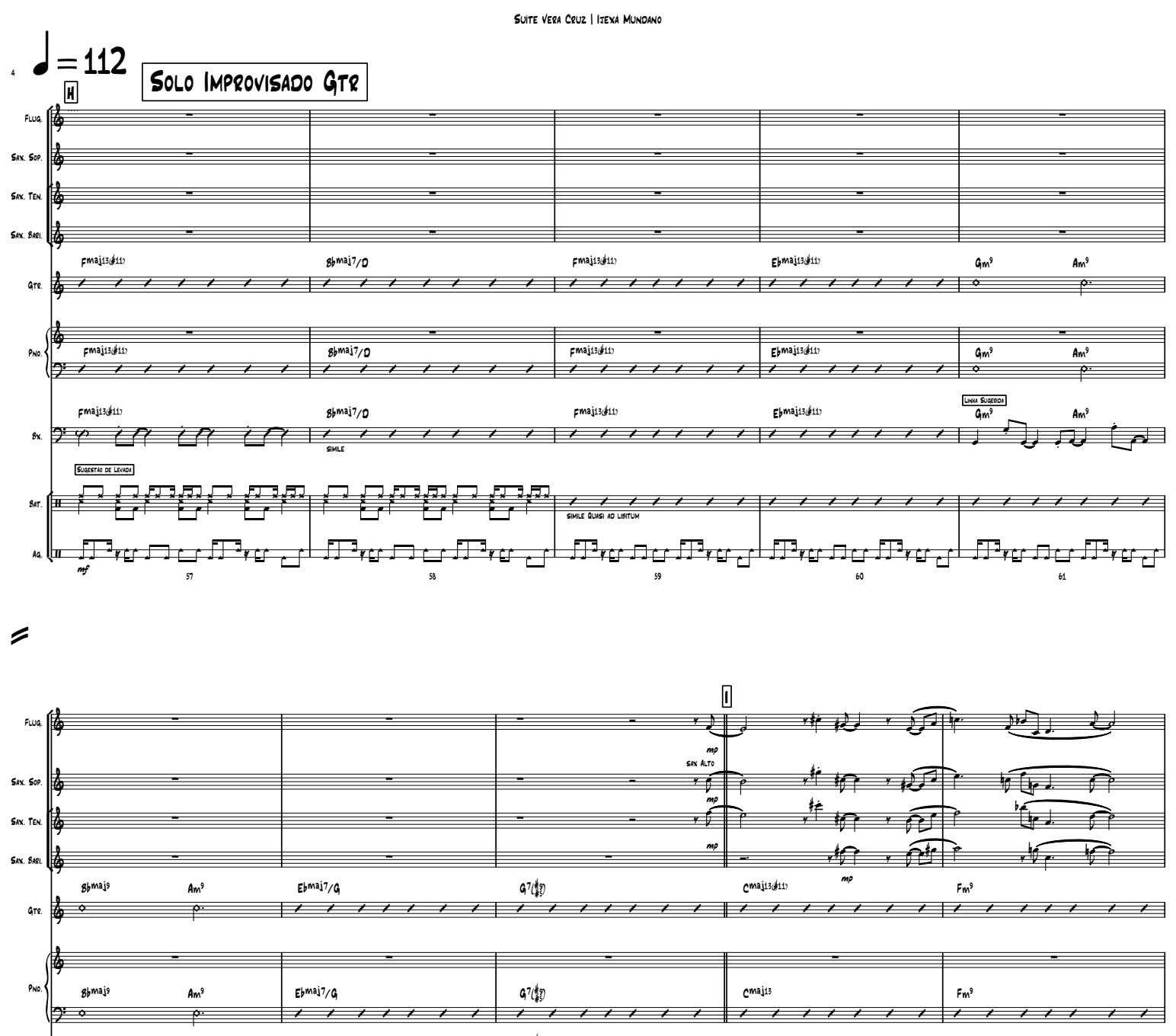

Q6.

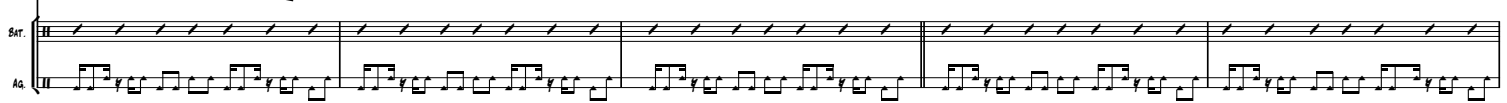

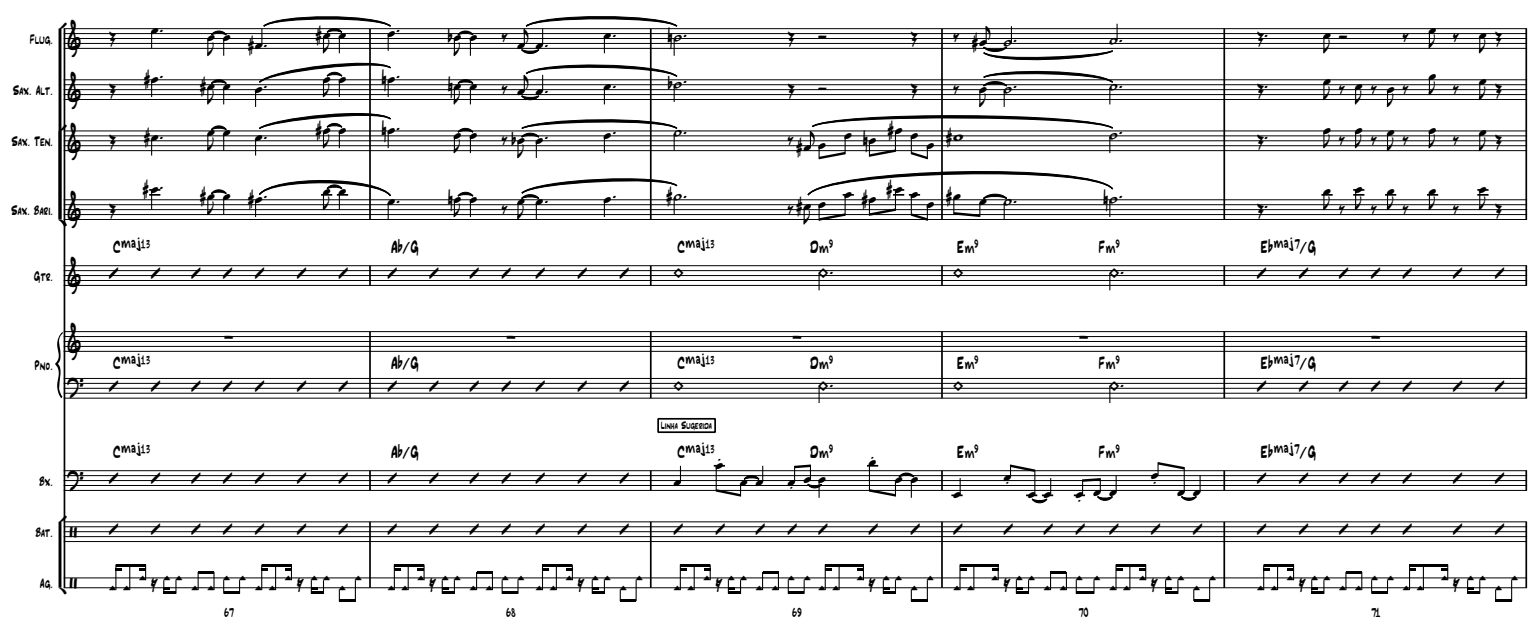



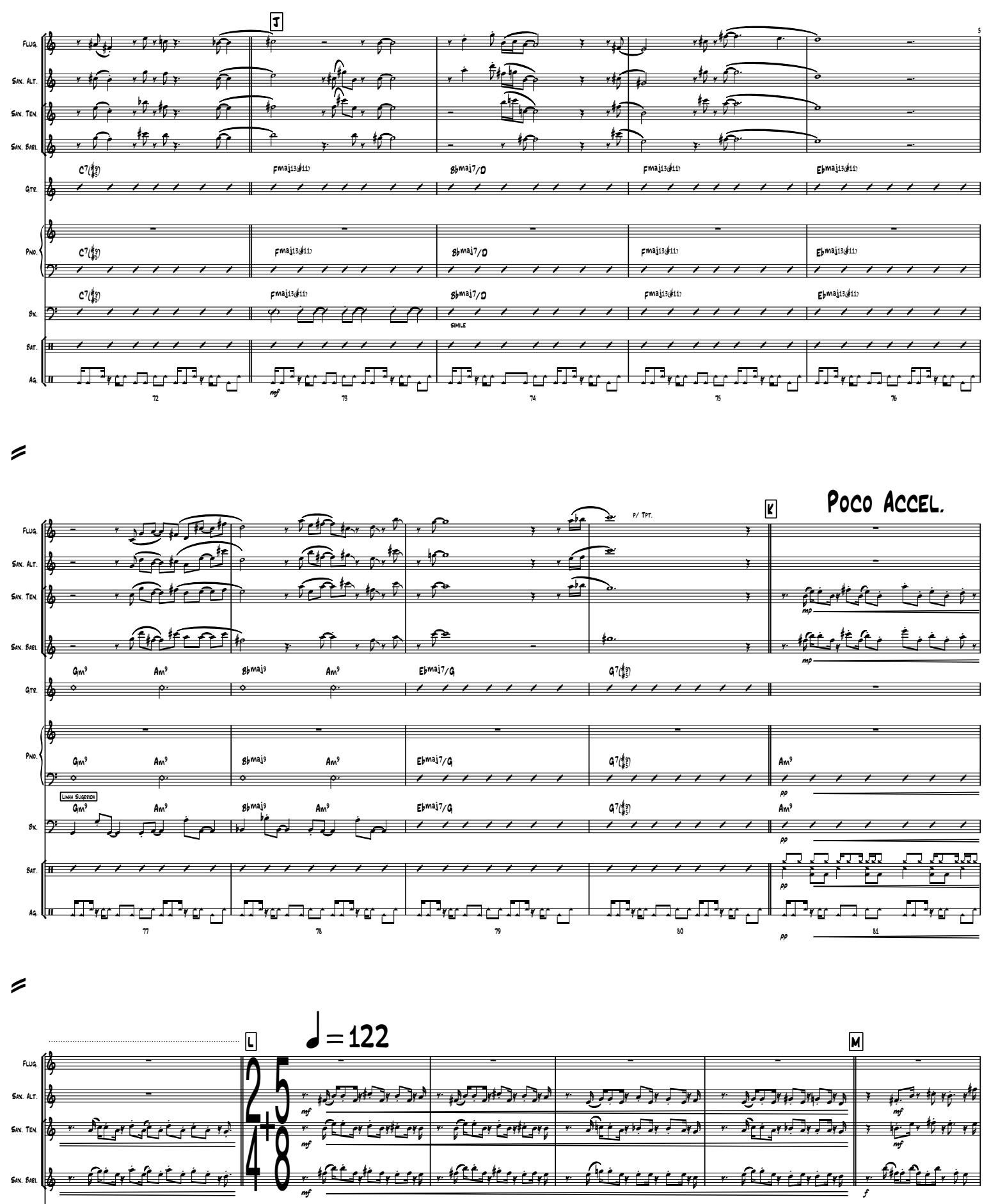

ar

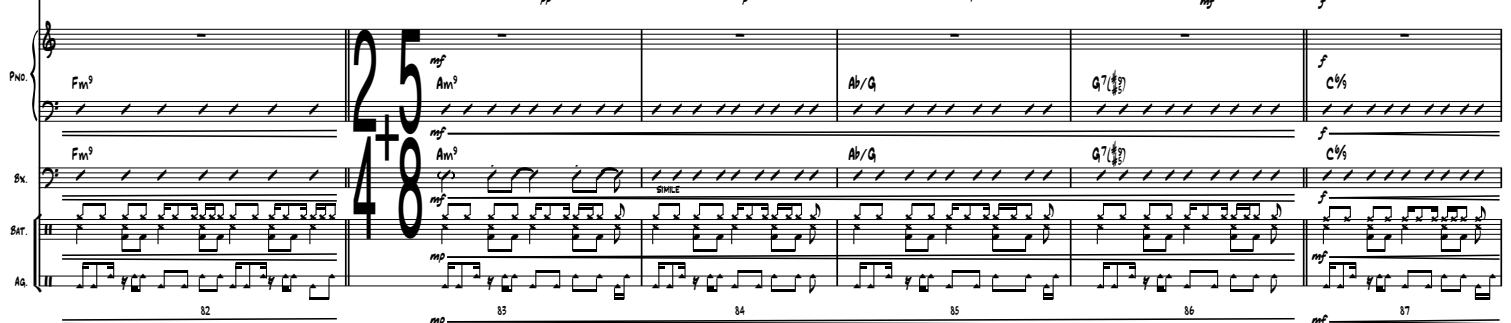



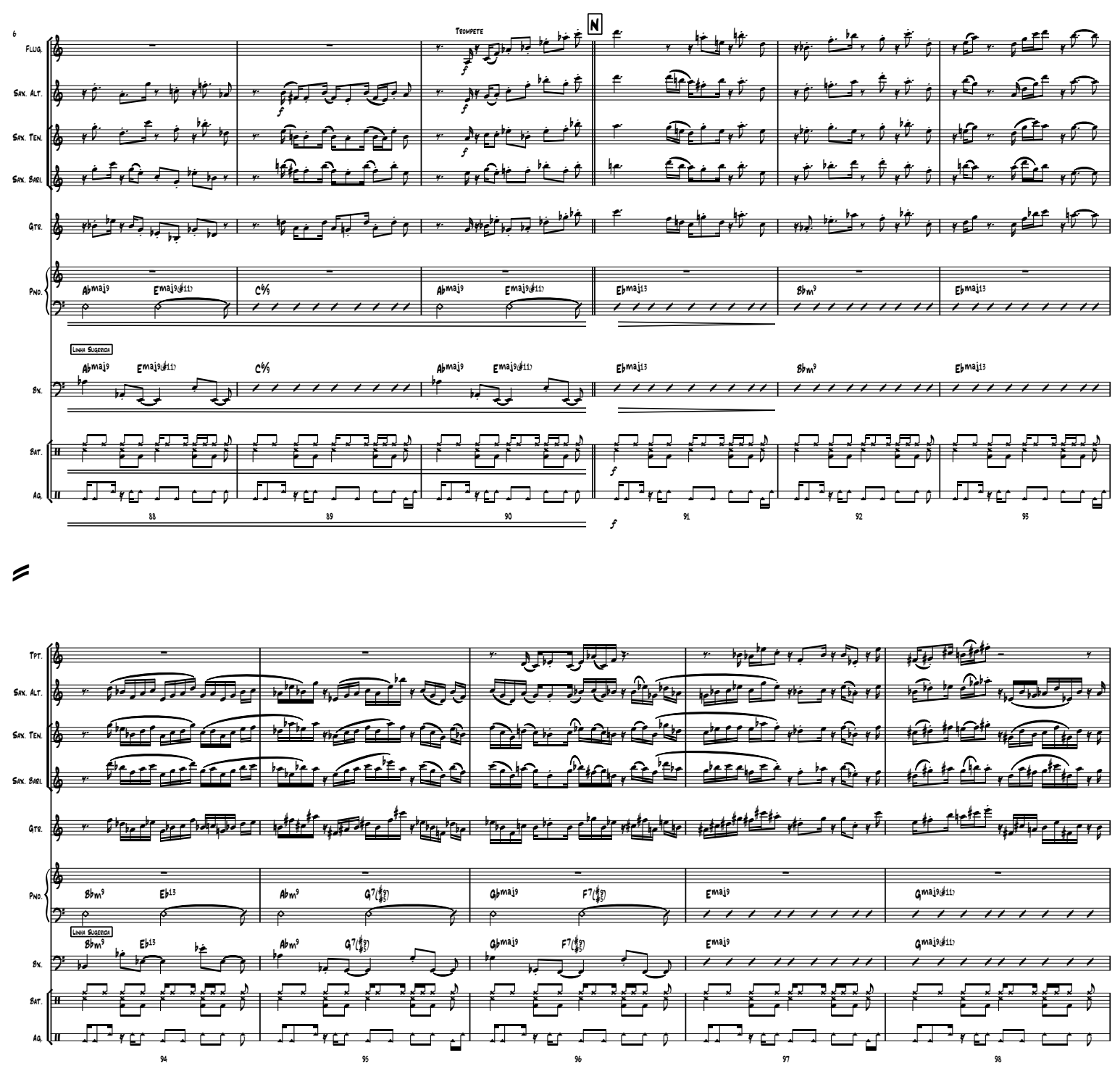

0

(12) 

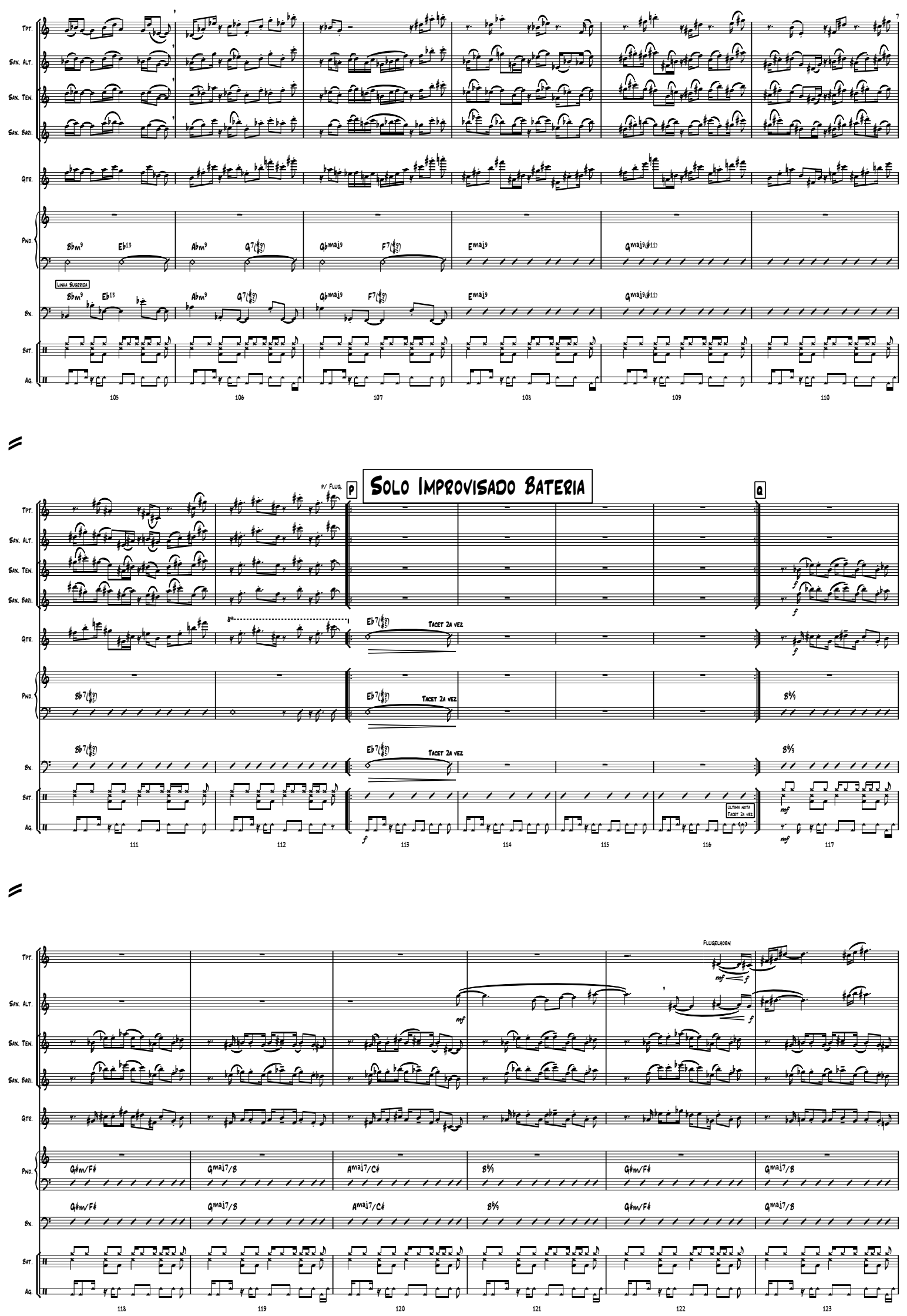

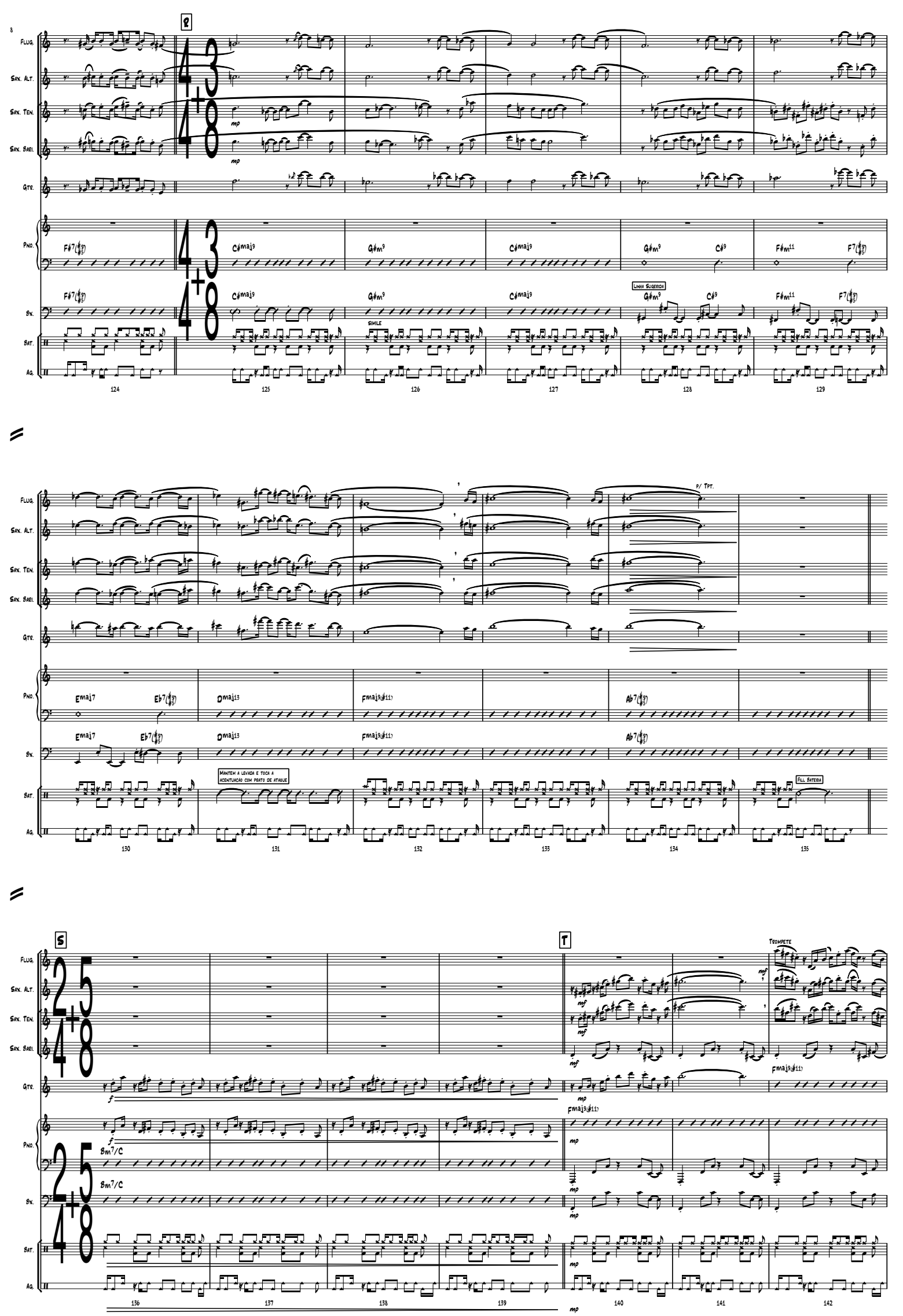
SUITE VERA CQUZ | IJEXA MUNoANo
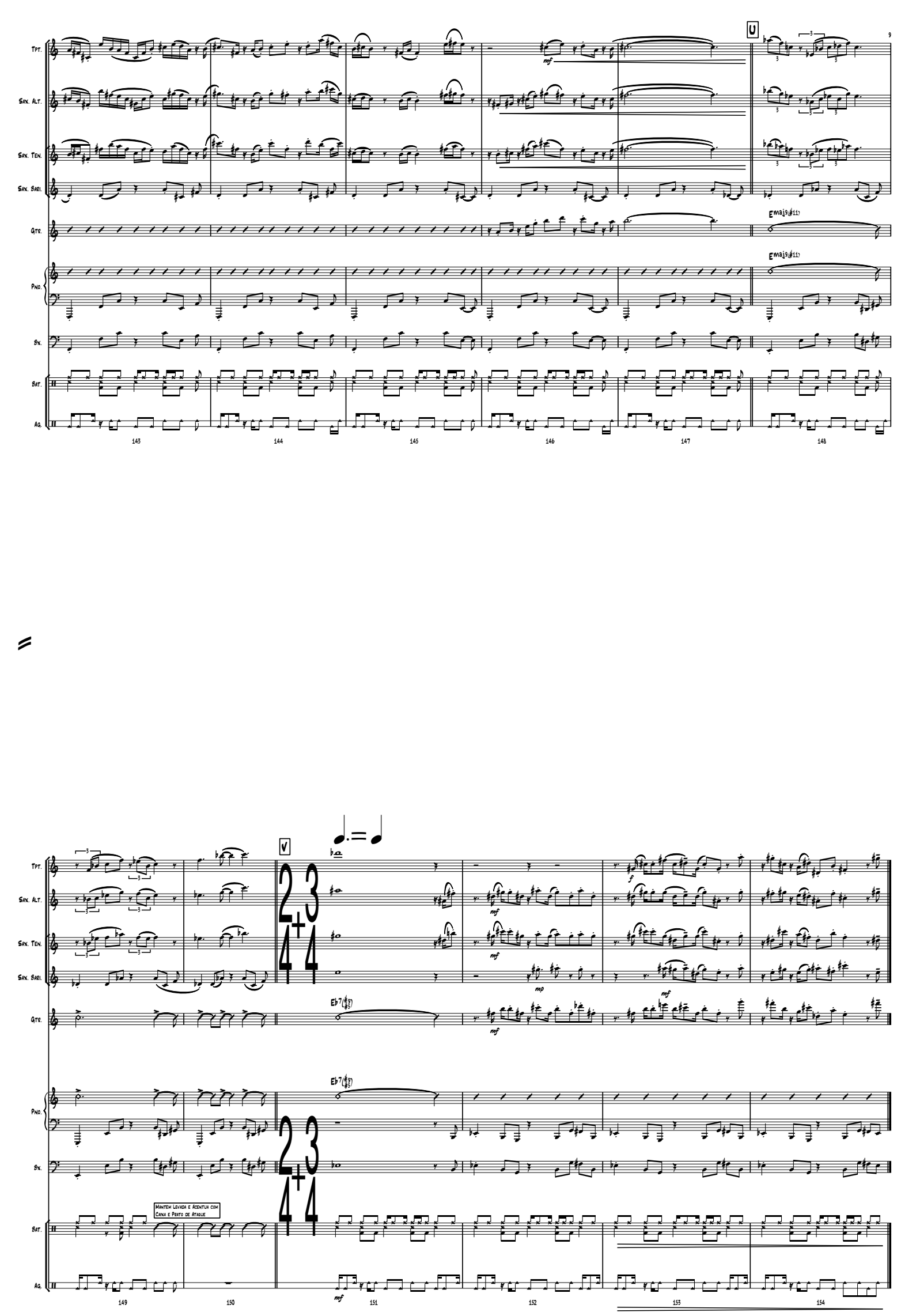